\title{
The Eastern Pacific ITCZ during the Boreal
}

\section{Spring}

\author{
Guojun $G u^{*}$
}

Goddard Earth Sciences and Technology Center,

University of Maryland Baltimore County, and Laboratory for Atmospheres, NASA/Goddard Space Flight Center, Greenbelt, MD

Robert F. Adler

Laboratory for Atmospheres,

NASA/Goddard Space Flight Center, Greenbelt, MD

Adam H. Sobel

Department of Applied Physics and Applied Mathematics, and

Department of Earth and Environment Sciences

Columbia University, New York, NY

\author{
March 2004 \\ Journal of the Atmospheric Sciences
}

\footnotetext{
${ }^{*}$ Corresponding author's address: Guojun Gu, Code 912, Goddard Space Flight Center, Greenbelt, MD
} 


\title{
The Eastern Pacific ITCZ during the Boreal Spring
}

\author{
Guojun Gu, Robert F. Adler and Adam H. Sobel
}

\section{Popular Summary}

The intertropical convergence zone (ITCZ) is a narrow band of tropical convection and rainfall in the Pacific and Atlantic, generally staying in the north hemisphere. The variations in its latitudinal locations and intensity can effectively influence weather and climate around the world. In the eastern Pacific, two ITCZs across the equator are often observed during MarchApril. Why and how this unusual phenomenon appears in this region are not very clear. The purpose of this study is to document this phenomenon using the 6-year (1998-2003) rainfall products from the Tropical Rainfall Measuring Mission (TRMM).

The double ITCZ phenomenon exists during March-April in the four TRMM years (19992002). There seems to be a competition for rainfall between the south and north hemispheres during this season. When one of the two rainfall maxima representing the ITCZ is strong, the other tends to be weak. However, the total rainfall over the two hemispheres (from the equator to about $15^{\circ} \mathrm{N}$ or $15^{\circ} \mathrm{S}$ ) shows much less variation. A similar result exists for SST, but it is not very convincing. Thus, at least some variations in the relative strength of the two rainfall maxima or the appearance of the double ITCZ may be independent of SST, which means that the atmosphere itself can modulate or determine the rainfall distribution to a certain extent. Another result is the importance of the cold SST over the equator. A cold equator is essential to the existence of the double ITCZs. However, too cold the equator is not preferred by the double ITCZs. These conclusions are generally confirmed by a 25-year (1979-2003) monthly rainfall dataset from the Global Precipitation Climatology Project (GPCP). 


\begin{abstract}
The 6-year (1998-2003) rainfall products from the Tropical Rainfall Measuring Mission (TRMM) are used to quantify the Intertropical Convergence Zone (ITCZ) in the eastern Pacific (defined by longitudinal averages over $90^{\circ} W-130^{\circ} W$ ) during boreal spring (March-April). The double ITCZ phenomenon, represented by the occurrence of two maxima with respect to latitude in monthly mean rainfall, is observed in most but not all of the years studied. The relative spatial locations of maxima in sea surface temperature (SST), rainfall, and surface pressure are examined. Interannual and weekly variability are characterized in SST, rainfall, surface convergence, total column water vapor, and cloud water. There appears to be a competition for rainfall between the two hemispheres during this season. When one of the two rainfall maxima is particularly strong, the other tends to be weak, with the total rainfall integrated over the two varying less than does the difference between the rainfall integrated over each separately. There is some evidence for a similar competition between the SST maxima in the two hemispheres, but this is more ambiguous, and there is evidence that some variations in the relative strengths of the two rainfall maxima may be independent of SST.

Using a 25-year (1979-2003) monthly rainfall dataset from the Global Precipitation Climatology Project (GPCP), four distinct ITCZ types during March-April are defined, based on the relative strengths of rainfall peaks north and south of, and right over the equator. Composite meridional profiles and spatial distributions of rainfall and SST are documented for each type. Consistent with previous studies, an equatorial cold tongue is essential to the existence of the double ITCZs. However, too strong a cold tongue may dampen either the southern or northern rainfall maximum, depending on the magnitude of SST north of the equator.
\end{abstract}

20771, USA. E-mail: ggu@agnes.gsfc.nasa.gov 


\section{Introduction}

Of the global tropical oceans, the eastern Pacific has perhaps the strongest annual cycle (e.g., Mitchell and Wallace 1992; Li and Philander 1996). Intense air-sea interactions in this region result in a cold tongue-Intertropical Convergence Zone (ITCZ) complex during the boreal summer and fall. A narrow band of frequent deep convection (i.e., the ITCZ) appears between $5^{\circ} N-10^{\circ} N$, associated with warm sea surface temperature (SST), while a large area of cold SST $\left(<26^{\circ} C\right)$ and infrequent deep convection occurs near and south of the equator. During the boreal spring, two ITCZs, as represented by monthly mean rainfall, are usually observed straddling the equator (Lietzke et al. 2001; Halpern and Hung 2001; Zhang 2001). This double ITCZ is coincident with the occurrence of relatively high SST (compared to immediately neighboring regions, or the same region at other times of year) along and south of the equator, and with seasonal weakening of southeasterly trade winds (e.g., Hayes et al. 1989; Kessler et al. 1998).

Using satellite-observed cloud data, Hubert et al. (1967) showed the presence of two convective zones in the eastern Pacific during March-May 1967. However, they concluded that the double ITCZ is not a characteristic feature of the tropical circulation. Recent satellite observations have improved our knowledge of this phenomenon. General agreement seems to have been reached that a double ITCZ normally occurs in the eastern Pacific during the boreal spring (Zheng et al. 1997; Lietzke et al. 2001; Halpern and Hung 2001; Zhang 2001). Moreover, a recent study of high-resolution surface wind observations from the space-based scatterometer QuikScat found that the double ITCZ is discernible year-round in the Atlantic and eastern Pacific oceans, if it is defined using the surface convergence field rather than precipitation (Liu and Xie 2002). Liu and Xie (2002) used a short data record (only fully covering two episodes of the double ITCZs), and focused on surface wind; they did not include data for related fields such as rainfall and water vapor. Lietzke et al. (2001) described temporal (weekly and monthly) and spatial patterns of several ITCZ-related variables dur-

ing boreal spring in the eastern Pacific using the Special Sensor Microwave/Temperature-2 (SSM/T-2) derived cloud and water vapor, the Microwave Sounding Unit (MSU) derived 
rainfall, and the European Remote Sensing satellite (ERS-1 and ERS-2) scatterometer wind field. Their study was primarily concentrated on three years, i.e., 1995-1997.

With the availability of 6-season (1998-2003) high-quality satellite rainfall observations from the Tropical Rainfall Measuring Mission (TRMM), the first objective of this study is to characterize the spatial and temporal variation of convection and rainfall in the eastern Pacific during boreal spring with a specific interest in the occurrence of the double ITCZs. Compared to Lietzke et al. (2001) and Liu and Xie (2002), we use different and longerrecord satellite observations including 6-season TRMM rainfall, and TRMM Microwave Imager (TMI) cloud, water vapor and SST. The year-to-year variation of the double ITCZs is emphasized, and shorter time scale evolution within each year is also examined.

Our second objective is to describe the observed relationships between the different variables studied here. Specifically, wc wish to clarify what kind of SST meridional profiles are generally preferred by the double ITCZs (defined here by precipitation, rather than surface convergence, unless stated otherwise), and to document the relative positions of maxima in the different variables. These issues are relevant for validating (or defining errors in) double ITCZs simulated in general circulation models, and perhaps also for testing theories for the mechanisms by which SST controls deep convection.

Details of the data sets are described in section 2. In section 3 , the relationship among tropical deep convection, SST, and surface wind fields on monthly and weekly time scales are examined using the 6-year (1998-2003) TRMM rainfall products, 6-year (1998-2003) TMI SST estimates and 4-year (2000-2003) Quikscat wind fields, respectively. Based on the previous conclusion that the double ITCZs are primarily observed in March and April (e.g., Lietzke et al. 2001; Zhang 2001), our monthly analysis will be concentrated on this season. The associations between rainfall and SST are further investigated in section 4 by means of a 25-year (1979-2003) rainfall product from the Global Precipitation Climatology Project (GPCP) and the 22-year (1982-2003) Reynolds SST (Reynolds et al. 2002). Finally, conclusions and implications of the study are given in section 5 . 


\section{Data}

TRMM products 3B43 (monthly) and 3B42 (daily) are used to describe the ITCZ-related convection and rainfall. In particular, the monthly mean product (3B43) is used to define the ITCZ in this study. These two datasets are produced by using (nearly) coincident TRMM Combined Instrument (TCI) [the combined algorithm using both the TMI and Precipitation Radar (PR)] and Visible and InfraRed Scanner (VIRS) data, to calibrate the geo-InfraRed (IR) rain rate (Adler et al. 2000). This strategy provides much better rain rate estimates than simple fixed-calibration geo-IR estimates, but with the same superior time sampling as the latter. The datasets are archived on a $1^{\circ} \times 1^{\circ}$ latitude-longitude grid, and extend from January 1998 to present.

The monthly and weekly TMI SST data used here are retrieved from the TMI on board the TRMM satellite. TMI can measure SST in the presence of overlying cloud, if the cloud is not precipitating. This is a distinct advantage over IR estimates, which require a cloud-free field of view (Wentz et al. 2000). The data cover a global region extending from $40^{\circ} S$ to $40^{\circ} \mathrm{N}$ at a spatial resolution of $0.25^{\circ}$ [Detailed algorithms can be found in Wentz (1997)]. TMI-derived cloud liquid water and column water vapor data are also used; they have the same spatial coverage and resolution as the TMI SST.

Surface wind fields are obtained from the SeaWinds scatterometer on board the QuikScat satellite (Liu et al. 1998; Liu and Xie 2002). Monthly and weekly products from January 2000 to May 2003 are used, extending from $89.875^{\circ} S-89.875^{\circ} \mathrm{N}$ with a spatial resolution of $0.25^{\circ}$.

A long-record (1979-2003) monthly mean rainfall dataset from the GPCP project is used to confirm the results from the TRMM rainfall products and to provide a preliminary climatology of the ITCZ during the boreal spring. On a global $2.5^{\circ} \times 2.5^{\circ}$ grid, the data is combined from various information sources (Adler et al. 2003): the IR rainfall estimates from geostationary and polar-orbiting satellites, the microwave estimates from Special Sensor Microwave/Imager (SSM/I) data, and surface gauge data from the Global Precipitation Climatological Centre (GPCC). For this climatology, the monthly mean SST of Reynolds $e t$ 
al. (2002), archived on $1^{\circ} \times 1^{\circ}$ grids for the years $1982-2003$, was used.

\section{TRMM years (1998-2003)}

\subsection{Monthly mean}

Fig. 1 shows the monthly mean rainfall and SST in boreal spring during the six TRMM years (1998-2003). Two distinct rainfall maxima appear on either side of the equator from the central to eastern Pacific during March-April. As found in previous studies, the double ITCZ appears to be a regular feature within the large-scale annual cycle in the eastern Pacific. In February and May, two rainfall peaks can also be seen, but the southern peak is mostly west of $130^{\circ} \mathrm{W}$ and perhaps should be associated with the South Pacific Convergence Zone (SPCZ).

The spatial distribution of surface rainfall generally follows that of SST. The equatorial cold tongue becomes weak during March-April, but is still discernible. North of the equator, the ITCZ gradually strengthens from February to May, concomitant with a steady SST increase. South of the equator, the SST attains its highest values in March and April in the eastern Pacific (east of about $130^{\circ} \mathrm{W}$ ). It seems that the occurrence of the southern rainfall peak is favored by a weak but discernible equatorial cold tongue and warmer SST $\left(>27^{\circ} C\right)$ south of the equator, generally consistent with previous studies (e.g., Lietzke et al. 2001; Zhang 2001).

\subsubsection{Rainfall, SST, and surface pressure}

Relationships between rainfall, SST, and surface pressure (from the NCEP/NCAR reanalysis project) are further examined for each year by comparing their respective meridional profiles, averaged over $90^{\circ} W-130^{\circ} W$ (Figs. 2 and 3). The composite ITCZ structures in Lietzke et al. (2001), in contrast, were based on the fields averaged over a region between $90^{\circ} \mathrm{W}-150^{\circ} \mathrm{W}$. Inspection of Fig. 1 shows that this longitude range includes two distinct 
SST maxima south of the equator. In the western portion, closer to $150^{\circ} \mathrm{W}$, the latitudinal SST maximum is further south and quite distinct from that further east. Although the rainfall maximum is continuous, we generally consider the western SST maximum to be associated with the SPCZ, distinct from the eastern Pacific ITCZ. We focus on averages only over the eastern ITCZ, defined here as the region between $90^{\circ} \mathrm{W}-130^{\circ} \mathrm{W}$, and find that this (perhaps in addition to the different data sets used) makes some difference in the results.

In 1998, warm equatorial SST $\left(>28^{\circ} \mathrm{C}\right.$ between $\left.10^{\circ} S-10^{\circ} \mathrm{N}\right)$ occurs in both March and April without any significant SST minimum along the equator. In that year, the intense rainfall band is broad and extends continuously from $5^{\circ} S$ to $5^{\circ} N$, though a northern peak does appear in March. This is consistent with the notion that the double ITCZ tends not to occur during the El Niño events because of the disappearance of the equatorial cold tongue (e.g., Zhang 2001).

In almost all the months shown, the surface pressure has a very broad minimum centered approximately at the equator, with essentially zero gradient between approximately $5^{\circ} S-$ $5^{\circ} \mathrm{N}$. In some cases there is a slight hint of a very weak local maximum within'that minimum, right on the equator.

In the four double ITCZ years [i.e., 1999, 2000, 2001, and 2002], local SST maxima appear on both sides of the equator, separated by a minimum on the equator. Particularly in March, the southern SST peaks are at least comparable in magnitude to their northern counterparts. The equatorial cold tongue in these four years is considerably weaker than in 2003 according to the difference between the equatorial SST and off-equator SST maxima. In the double ITCZ years, the rainfall peaks in March are generally found a few degrees of latitude poleward of the SST peaks, whereas the two tend to be collocated in April. In 1998 and 2003, the rainfall peaks are roughly collocated with the SST maxima. These findings are systematically different from Lietzke et al. (2001). They found that the rainfall maxima tend to be equatorward of the SST maxima. As mentioned above, their conclusions were based on averages over $90^{\circ} \mathrm{W}-150^{\circ} \mathrm{W}$ which are partly influenced by the more southern (compared to the eastern SST maximum) SST associated with the SPCZ. 
Tomas and Webster (1997) stated that SST and rainfall maxima tend to be collocated when the cross-equatorial surface pressure gradient is weak, and displaced more from one another when it is strong. Considering all the months shown in Figs. 2 and 3, the relative displacement of the SST and precipitation maxima ranges from zero to perhaps five degrees at most - in all cases significantly less than the distance between the two ITCZs. To the extent that this qualifies as a "small" displacement, these results appear consistent with the findings of Tomas and Webster (1997). Such displacements as do occur tend to place the rainfall maxima systematically poleward of the SST maxima. Tomas and Webster (1997) also stated that rainfall maxima tend to lie equatorward of surface pressure troughs. Unusual in other ways, the eastern Pacific double ITCZs in boreal spring are clearly an exception to this general rule as well. Although the pressure troughs are so broad in Figs. 2 and 3 that it is hard to pinpoint the absolute minima with precision, in most cases - April 1998 being the clearest counterexample - the precipitation maximum lies either distinctly poleward of the pressure minimum, or at least near the poleward edge of the region of near-zero gradient.

\subsubsection{Competition between the two ITCZs}

Inspection of Figs. 2 and 3 leads to the impression that, from year to year and month to month (within boreal spring), there is a competition between the northern and southern ITCZ (as measured by rainfall), with an approximate conservation of the total rainfall integrated over both. In other words, when one ITCZ is particularly strong, the other is weak, and when both are of comparable magnitude, that magnitude is less than the magnitude of the stronger one at times in which one dominates. 1998, the strong El Niño year, is again the exception to this.

This is made more quantitative by Figs $4 \mathrm{a}$ and $4 \mathrm{~b}$. To produce this figure, we first compute the total integrated rainfall over the northern and southern ITCZs, $P_{N}$ and $P_{S}$. These are defined by integrals from $0.5^{\circ} \mathrm{N}$ to $14.5^{\circ} \mathrm{N}$ and $14.5^{\circ} S$ to $0.5^{\circ} S$, respectively. We then plot the sum, $P_{N}+P_{S}$, as a function of the difference $\left|P_{N}-P_{S}\right|$, in a scatter plot, where each point is one of the months shown in Figs. 2 and 3. Fig. 4a does this from 
the TRMM data. Excluding 1998, we see that the range of variation in the sum, which is the total rainfall over both ITCZs together, is smaller than the range variation in the difference. Fig. $4 \mathrm{~b}$ shows the same thing, but computed from the longer-record GPCP data. In this case, again excluding the El Niño years, the scatter is somewhat larger, and there is a slightly larger linear trend (indicating a tendency towards more total rainfall when the northern ITCZ is stronger than the southern), but qualitatively, the result is similar to Fig. 4a. These results quantify the notion in the previous paragraph, that there is an apparent competition between the two ITCZs, with approximate conservation of the total rainfall in both together. The situation may be compared to that of a single convective zone whose location shifts from month to month or year to year, while its intensity changes relatively little; the difference here is that, the El Niños excluded, the rainfall skips the equator and rather is "exchanged" between two rclatively fixed locations at a finite distance from one another.

It is natural to ask how much of this result is due to coupled interaction, and how much is due to internal atmospheric dynamics. For example, Hack et al. (1989) suggested that a stronger northern ITCZ may suppress the southern one through large-scale subsidence, a mechanism which could operate independently of SST, echoing arguments made earlier by Graham and Barnett (1987). On the other hand, if the competition between the two ITCZs is due to coupled interaction (or, for that matter, ocean processes alone, which would then influence the atmosphere through their effect on SST), we would expect to see a competition in SST similar to that seen in precipitation. In that case, the precipitation signal could be viewed as an essentially deterministic response to SST. In Figs. 4c and $4 \mathrm{~d}$, we define an $S S T_{N}$ and $S S T_{S}$ exactly analogously to $P_{N}$ and $P_{S}$, and making the same plots as in Figs. 4a and 4b. Figs. 4c and 4d show the TMI and Reynolds SST, respectively. In Fig. 4c, we see that the TMI SST does show a competition similar to that seen in precipitation, with a warmer sea surface in one hemisphere tending to be associated with a cooler one in the other, such that the SST integrated over both hemispheres changes relatively little. The Reynolds $\mathrm{SST}$, in Fig. 4d, does not corroborate this, having much greater variations in $S S T_{N}+S S T_{S}$, 
both scatter and a decreasing trend with increasing $\left|S S T_{N}-S S T_{S}\right|$. Comparing Figs. 4b and $4 \mathrm{~d}$ shows, based on the longer data sets, that although total integrated SST is lower when the northern SST maximum exceeds the southern one by a larger margin, the total integrated rainfall has a slight tendency to increase in that circumstance. This may be counterintuitive to the extent that we expect rainfall and SST to be correlated, but actually this relationship applies usefully only to deviations from the larger-scale mean. In means over the entire tropics, for example, SST and rainfall are at most very weakly correlated (Su and Neelin 2003).

We are thus left with a somewhat ambiguous result. Although the TMI SST data seem to indicate that the competition in precipitation is the deterministic result of a similar competition in SST, the TMI record is relatively short compared to the Reynolds data, which give a different answer. Even in the TMI data, we can find evidence for a non-deterministic component of the precipitation. The TMI SST profiles shown in Fig. 3 are nearly identical in April 1999 and 2003, while the associated rainfall profiles are very different, with a strong southern rainfall maximum in 1999 and almost none in 2003. Either precipitation is exquisitely sensitive to very small SST differences, or this is a fairly dramatic example of the lack of an entirely deterministic, instantaneous relationship between rainfall and SST, at least on a monthly mean basis. The SST profiles differed more in March of those two years, with a significantly greater value in the northern maximum than the southern one in 2003 , and a slightly greater value in the southern maximum than the northern one in 1999. Perhaps some atmospheric memory of the suppressed southern ITCZ (and strong northern one) is able to persist from March to April in 2003, despite the southern SST increase. For example, the water vapor field might carry such a memory, with descent during March 2003 leading to a relatively dry troposphere persisting into April, as is seen to some degree in Fig. 7 below, which could suppress precipitation. To further explore the possible non-deterministic component of precipitation, scatterplots of rainfall, SST and surface convergence (more results and discussions about surface convergence are in section 3.1.4) are shown at three different latitudinal belts (Fig. 5): $5^{\circ} S, 0^{\circ}$ and $5^{\circ} N$. Grossly, linear correlations can be found among 
these variables. However, along $5^{\circ} S$, roughly the location of the southern ITCZ, only weak correlations seem to exist between rainfall and SST, and between rainfall and surface convergence, quite different than over the equator and along $5^{\circ} \mathrm{N}$. It seems that a lower SST and weaker convergence at $5^{\circ} S$ may produce the same amount of rainfall as at $5^{\circ} \mathrm{N}$, further emphasizing the possible role of internal atmospheric dynamics.

\subsubsection{Rainfall, cloud liquid water and water vapor}

Monthly mean profiles of TMI column water vapor and cloud liquid water are illustrated in Figs. 6 and 7 for comparison to surface rainfall. The peaks of these three variables are generally collocated. During the months when a southern ITCZ is well defined, water vapor and cloud liquid water have similar regional maxima in the Southern Hemisphere, though differences in the two fields' structure can be readily found at a finer level of detail. Column water vapor is much more smoothly distributed across the equator than the other two variables. Particularly, in March 1998 one water vapor peak is observed right over the equator, whereas rainfall and clouds have maxima at the latitude of about $2^{\circ}-3^{\circ} N$. Local maxima in cloud liquid water need not always be accompanied by comparably strong rainfall peaks, for instance, south of the equator in 2003. Similarly, a certain amount of cloud liquid water is always observed south (north) of about $10^{\circ} S\left(10^{\circ} \mathrm{N}\right)$, whereas no significant rainfall occurs there. These cloud liquid water are probably related to low-level stratus clouds over relatively cold waters (e.g., Philander et al. 1996). Over somewhat warmer waters, there is presumably some signal from trade cumulus or midlevel, weakly or nonprecipitating cumulus congestus (e.g. Johnson et al. 1999).

\subsubsection{Rainfall and convergence}

We examine here the spatial relationships between surface convergence field and rainfall, taking advantage of the availability of the 4-season (2000-2003) high-quality QuikScat surface wind product. Due to the much smaller contribution from the zonal wind component near the equator (e.g., Liu and Xie 2002), the surface convergence $(C V)$ field is estimated as 
the meridional gradient of meridional wind component, i.e., $C V=-\nabla \cdot \vec{V} \approx-\frac{\partial v}{\partial y}$, here $\vec{V}=(u, v)$.

Meridional profiles of surface convergence and rainfall in March and April are shown in Fig. 8. Two convergence peaks are observed straddling the equator, concomitant with a divergence or weaker convergence (i.e., in March 2002) zone near the equator. In March, the convergence in the Southern Hemisphere is stronger than, or at least comparable to its northern counterpart, with the exception of 2003. The spatial structures of the rainfall and convergence fields show salient differences. Rainfall peaks are not always located within the most intense convergence areas. The convergence maxima tend to be somewhat closer to the equator than the rainfall maxima, particularly in the Southern Hemisphere, with the convergence maxima roughly matching those in the SST (Figs. 2 and 3).

\subsubsection{Meridional wind and SST}

Previous studies have proposed two distinct mechanisms for control of tropical surface wind by SST. Here, we show the observed relationship between SST and meridional wind component, since the latter generally dominates the surface convergence field near the equator. Lindzen and Nigam (1987) proposed that SST gradients induce surface pressure gradients by thermal and hydrostatic adjustment. These pressure gradients then force surface wind perturbations. In general, this argument predicts that the maximum (minimum) wind is expected where the SST gradients are largest (smallest). Wallace et al. (1989) proposed that warmer (colder) SST enhances (inhibits) vertical turbulent mixing which eventually induces the increase (decrease) of surface wind. Thus, the regionally warmest (coldest) SST generally corresponds to maximum (minimum) surface wind speed if this mechanism becomes active. Obviously, these two distinct mechanisms predict different locations of maximum (minimum) surface wind relative to the spatial distribution of SST. Another idea still is that upper-level convective heating drives surface winds, as made most famous by Gill (1980; see also Chiang et al. 2001). This view does not predict a specific relationship between SST and surface wind, but inasmuch as we presume deep convection (and thus low-level convergence) 
to maximize at or near SST maxima, this view generally leads us to expect strong surface winds to be broadly associated with regions of SST gradient, similar to the Lindzen-Nigam view. In fact, the Gill and Lindzen-Nigam models are mathematically isomorphic (Neelin 1989).

In general, we expect the Wallace et al. mechanism to be operative when the SST is not too warm, so that warming the SST can make the difference between a relatively stable boundary layer and one containing more vigorous shallow convection, which mixes upperlevel momentum down to the surface. If the SST is warm enough that shallow convection is already prevalent, then a further increase may have no effect, or may cause the onset of deep convection, whose effects on the momentum budget are less clear.

Monthly mean meridional profiles of TMI SST and QuikScat meridional wind are examined in Fig. 9 for March and April. As suggested in Liu and Xie (2002), meridional wind shows two ways of contributing to surface convergence: surface confluence (generally north of the equator) meaning that northerly and southerly flows meet, and southerly wind deceleration, without a change of sign of the meridional wind (mostly south of the equator). In March of 2000, 2001 and 2002 (namely, the three double ITCZ years), the relationship between the SST and meridional wind seems quite different from that in 2003 in which the southern ITCZ is negligible. In the three double ITCZ years, the surface confluence line is either near the equator or even into the Southern Hemisphere. The strongest southerly wind is seen about $5^{\circ}$ south of the maximum SST. Intense southern SST gradients are thus likely responsible (whether by the Lindzen-Nigam mechanism, or via the influence of SST on convection, and then a Gill mechanism) for the southerly wind acceleration between $5^{\circ} S-10^{\circ} S$, which is associated with the near-equatorial southern convergence. In March 2003, the maximum southerly wind is approximately collocated with the SST peak, which might suggest that the SST-forced boundary-layer mixing processes became dominant (e.g., Wallace et al. 1989; Hayes et al. 1989). This makes physical sense, since the southern rainfall maximum was very weak in 2003 , so that the southern region was in a more shallow-convective regime, in which the atmosphere over the SST maximum might have had more vigorous shallow 
convection than neighboring regions (as opposed to having deep convection). In April, the surface confluence line moves back to the Northern Hemisphere in all four years; a southerly wind minimum is seen near the equator together with a much more evident cold SST tongue, which seems to suggest that the SST-forced boundary-layer mixing processes become more important. Thus, there is arguably evidence, at one time and place or another, for all the possible mechanisms of surface wind forcing by SST during boreal spring.

\subsection{Weekly variation}

Weekly rainfall averaged from the TRMM daily product (3B42) and weekly TMI SST in the eastern Pacific during the boreal spring are shown in Fig. 10. Generally speaking, significant rainfall appears when and where SST is over $26^{\circ}-27^{\circ} \mathrm{C}$ (e.g., Gadgil et al. 1984; Graham and Barnett 1987; Fu et al. 1990). This eastern Pacific threshold value is slightly lower than that found in the western Pacific and Indian oceans, as found earlier by Fu et al. (1990). The most intense rainfall events were observed in 1998, in which year the strong precipitation fell without (spatial) interruption across the equator, which was extensively covered by warm water $\left(>28^{\circ} \mathrm{C}\right)$ due to the strong El Niño. In 1999, 2000, 2001 and 2002 (the four double ITCZ years), warmer SST (over $26^{\circ} \mathrm{C}$ ) extends to the Southern Hemisphere, and thus the equatorial cold tongue becomes weaker approximately during day 60-130. Concurrently, the major rainfall zones shift south of the equator. If a time-mean meridional rainfall profile is calculated between day 60 and 100, the northern ITCZ is barely discernible in 1999 and 2000. In contrast, rainfall events south of the equator are negligible in 2003 , though a relatively warm water area can still be observed along $5^{\circ} S$ roughly from day 60 to 140 .

As in Figs. 2 and 3, but now at a weekly time scale, we see that surface rainfall does not exactly follow SST, though it is often close to doing so. Particularly in the four double ITCZ years, major rainfall events south of the equator tend to occur along the southern boundary of the regions of greatest SST. After about day 120-130, the southern SST begins to drop, and the corresponding rainfall band thus disappears. Simultaneously, the northern ITCZ 
becomes significantly strengthened.

The weekly surface convergence field is also shown, using the weekly QuikScat wind vectors for the boreal spring during 2000-2003 (Fig. 11). Two bands of surface convergence are evident during the entire time perid (day 8-148), with a divergence zone meandering over the equator, consistent with Liu and Xie (2002). These two bands of convergence are not always associated with significant rainfall. The major rainfall events south of the equator only occur approximately during day $60-130$ in 2000,2001 and 2002 . In 2003 , no significant rainfall appears south of the equator, though there is still a salient (if somewhat weaker than in the other years) southern convergence zone. In the absence of deep convection and associated large-scale ascent in 2003 , presumably the mass ascending out of the boundary layer is diverging again only slightly higher up, in a shallow circulation of the type recently documented in this region by Zhang et al. (2004),

Weekly TMI cloud liquid water and column water vapor are depicted in Figs. 12 and 13, respectively. Surface rainfall bands are marked by the simultaneous presence of clouds and regional water vapor peaks. There seems to be essentially no phase-lag between rainfall and water vapor, consistent with a recent study which found the typical lag to be less than a day, too short to be visible in Figs. 12 and 13 (Bretherton et al. 2004). Major rainfall events south of the equator in the double ITCZ years are concurrent with southward (cross-equatorial) excursion of high column water vapor values and the appearance of significant cloud activity. However, as noted above, there are several cases in which cloud liquid water peaks and regional water vapor maxima are not accompanied by any significant rainfall. In 2003, there are three consecutively occurring regional maxima of cloud liquid water and water vapor south of equator, without much rainfall. It is possible that this lack of deep convection is caused dynamically, by enhanced subsidence associated with the intense northern convective band. As shown in Figs. 6 and 7, low-level stratus clouds are widely seen south (north) of $10^{\circ} S\left(10^{\circ} \mathrm{N}\right)$. 


\section{Climatological mean}

Meridional distributions of 25-year (1979-2003) monthly mean rainfall between $91.125^{\circ} \mathrm{W}-$ $131.125^{\circ} \mathrm{W}$ from GPCP are illustrated in Fig. 14 as well as the mean meridional profiles. Two rainfall peaks occur in March and April, showing the climatological characteristics of the double ITCZs. In February and May, only a single ITCZ appears north of the equator. These features are generally in agreement with the currently-archived TRMM observations (Figs. 1, 2 and 3).

For comparison, the mean meridional profiles of monthly rainfall data from the NCEP/NCAR reanalysis project are also shown (dashed lines in Fig. 14). The locations of the rainfall maxima from the NCEP/NCAR reanalysis project generally agree with those from the GPCP data, though a one grid point $\left(2.5^{\circ}\right)$ difference is found in several cases. In March and April, the magnitudes of the reanalysis rainfall peaks are similar to those of the GPCP ones. In May, the reanalysis data underestimate the northern rainfall peak but overestimate the southern one, compared to GPCP. The southern peaks in February and May suggest that erroneous double ITCZs exist in the reanalysis data. Presumably, this may be related to the influence of a numerical model on the reanalyses in this data-sparse region. The tendency to produce a double ITCZ where and when one doesn't exist in reality is a well-known feature of many numerical models (e.g., Mechoso et al. 1995).

Based on the relative intensity of rainfall peaks south $\left(P_{s}\right)$ and north $\left(P_{n}\right)$ of the equator, and rainfall intensity over the equator $\left(P_{e q}\right)$ during March-April (Fig. 14), we define four distinct ITCZ types (Table 1). The months corresponding to these ITCZ types are listed in Table 2. It shows that these four ITCZ types cover all possible aspects of the ITCZ in the eastern Pacific.

Composite meridional profiles of monthly rainfall are shown in Fig. 15a. Two major categories can be found: the double ITCZ cases (Type I) and the non-double ITCZ cases (Type II, III and IV). Type II generally represents El Niño events. Intense rainfall covers the equatorial belt in these cases, although there is often still a rainfall peak in the Northern Hemisphere (dashed line in Fig. 15a). For Type III and IV, in contrast, a single significant 
rainfall maximum is located either south or north of the equator. Furthermore, Type III can only be found in March.

Composite meridional profiles of SST between $91.125^{\circ} \mathrm{W}-131.125^{\circ} \mathrm{W}$ are depicted in Fig. 15b, corresponding to the ITCZ types. As shown by the TRMM observations (Figs. 2 and 3), higher SST is generally accompanied by greater rainfall. With a negligible equatorial cold tongue, the highest equatorial SST appears across the equator for type II, with a strong SST peak between $0^{\circ}-5^{\circ} N$ followed by intense mean rainfall. For the other three types, an equatorial cold tongue shapes two SST maxima. The intensities of the rainfall maxima do not exactly follow those of the SST maxima. In the Southern Hemisphere, the SST profiles look very similar and the SST maxima are comparable in magnitude for these three non-El Niño types, in contrast to the large rainfall differences. Although again it is the contrast between the SST maximum and the SST of the rest of the tropics (or at least the surrounding regions) that we expect to be important, the tropical mean SST primarily tracks ENSO indices such as Niño3 (Sobel et al. 2002). El Niños have been removed from Figs. $4 \mathrm{~b}$ and $4 \mathrm{~d}$. Thus, the result just described, if real and not an artifact of the data sets, presumably indicates again that some monthly mean rainfall variations can be induced by atmospheric dynamics, independently of SST.

Composite horizontal distributions of rainfall and SST are further displayed in Fig. 16. The type II ITCZ generally reflects the impact of the equatorial warming during El Niño events. The type I ITCZ shows two convective zones across the equator, roughly following the spatial distributions of SST. For Type III, mean convection and rainfall are very weak north of the equator, particularly east of $120^{\circ} \mathrm{W}$, but strong south of the equator. In contrast, the mean rainfall for Type IV is extremely strong in the northern hemisphere, while the southern ITCZ is negligible. Further comparing the SST patterns for these three non-El Niño types, we see that the SST does not show large variations south of the equator, as shown in Fig. 15. Large SST differences are observed in the regions over the equator and north of the equator. Compared with the double ITCZ type (Type I), Type III is accompanied by a colder equatorial region and much colder waters north of the equator, both of them being 
unfavorable for the northern ITCZ. For Type IV, however, SST is very warm north of the equator, and the equatorial cold tongue is relatively weak (compared with Type III), which tends to enhance (suppress) the northern (southern) ITCZ. It seems that the appearance and strength of the southern ITCZ is determined not only by the southern SST, but also by the SST over and north of the equator. This is consistent with the competition mechanism suggested the preceding section.

Lietzke et al. (2001) composited the meridional structures of rainfall and SST, and further proposed three types of atmospheric structures related to the eastern Pacific ITCZs during the boreal spring. Their classification was as well based on the meridional distributions of SST: (a) A symmetric meridional SST with an equatorial cold tongue during the La Niña years forcing two equally strong ITCZs; (b) An asymmetric meridional SST with an equatorial cold tongue and a stronger northern SST peak during the neutral years forcing a stronger northern ITCZ and a weaker southern one; (c) A broad warm equatorial SST during the El Niño years with one individual strong convective band covering the equatorial region. They ascribed the occurrence of a double ITCZ to an equatorial cold tongue. The results shown here are generally consistent with theirs. However, we subdivide the non-ITCZ years further into Type II, III and IV which correspond to three distinct spatial distributions of rainfall and SST.

\section{Summary and concluding remarks}

The eastern Pacific ITCZ during boreal spring is quantified by the 6 -season TRMM rainfall data. Two individual convective bands are observed straddling the equator during March and April in 1999, 2000, 2001 and 2002. The southern ITCZ becomes stronger than its northern counterpart in some cases. At times, deep convection can even shift entirely into the Southern Hemisphere for as much as several weeks. In the strong El Niño year 1998 , only one broad convective zone appears, right across the equator. In 2003, one intense convective band is located around $5^{\circ} \mathrm{N}$. 
The ITCZs, as quantified by rainfall maxima, generally are closely associated in both space and time with SST maxima. At a given time, rainfall maxima are displaced meridionally from SST maxima by no more than a few degrees. To the extent the two are displaced, rainfall maxima tend to lie poleward of SST maxima. This result is different from what is found if the longitudinal averaging range is extended further west, across greater zonal inhomogeneities in the SST field. The surface pressure field in March and April has a broad maximum on the equator, with the rainfall maxima lying generally clearly poleward of the pressure minimum, different from what is found in other seasons.

There appears to be a competition between the two ITCZs as measured by rainfall. When one is strong, there is a tendency for the other to be weak, with the total rainfall integrated over both varying less than the difference between the two. In the TRMM data, a similar signal is found in the SST, suggesting that the rainfall competition is a manifestation of coupled ocean-atmosphere dynamics. In the longer-record Reynolds SST data, such a signal is much less apparent, as there is much more variability in the total SST integrated over both ITCZs. This would tend to suggest more of an independent role for atmospheric dynamics in creating the rainfall competition. Even in the TMI data there is evidence for independent atmospheric dynamics, as April of 1999 and 2003 have very similar SST structures but very different rainfall structures, with a strong southern ITCZ in 1999 and almost none in 2003.

Superimposition of the SST and meridional wind fields yields some evidence for both SST-induced boundary layer pressure gradients and shallow convective momentum mixing as influences on the meridional wind. As found previously (Liu and Xie 2002), the double convergence zone derived from the QuikScat wind field appears to be a much more frequently observed phenomenon than are the two rainfall peaks often used to quantify the ITCZs in the eastern Pacific. The double ITCZ defined by convection and rainfall is only observed during boreal spring, and even then monthly and weekly mean rainfall do not always follow surface convergence patterns exactly. Water vapor and cloud liquid water maxima appear when and where significant mean convective and rainfall bands are observed, quantitatively consistent with the results shown in Zhang (2001) and Lietzke et al. (2001). However, in several cases 
regional water vapor and cloud liquid water peaks are not associated with significant rainfall.

Many of the double ITCZ features found in the TRMM data are confirmed by the longrecord data sets from the GPCP and NCEP/NCAR reanalysis project. Four types of the ITCZs are categorized based on the GPCP rainfall. The intense convective bands, particularly the southern ITCZ, seem to be determined not only by the local SST but also by the intensity of the equatorial cold tongue and surprisingly the SST north of the equator possibly through its impact on the regional atmospheric large-scale circulation.

\section{Acknowledgements.}

The authors would like to thank Dr. Chidong Zhang for his comments and suggestions. Mr. David Bolvin prepared the TRMM and GPCP rainfall data. Both TMI data and QuikScat wind vectors were downloaded from http://www.ssmi.com. The NCAR/NCEP reanalysis rainfall data was kindly provided by Dr. John Janowiak. The NCAR/NCEP reanalysis surface pressure data was provided by the NOAA-CIRES Climate Diagnostics Center, Boulder,Colorado, USA, from its Web site at http://www.cdc.noaa.gov. The NOAA OIv2 SST data were downloaded from ftp://ftpprd.ncep.noaa.gov/pub/cmb/sst/. This work is supported through the TRMM Science Team under the NASA Headquarters TRMM Program Scientist Dr. Ramesh Kakar. 


\section{References}

Adler, R. F., G. J. Huffman, D. T. Bolvin, S. Curtis and E. J. Nelkin, 2000: Tropical rainfall distributions determined using TRMM combined with other satellite and rain gauge information. J. Appl. Meteor., 39, 2007-2023.

Adler, R. F., G. J. Huffman, A. Chang, R. Ferraro, P. Xie, J. Janowiak, B. Rudolf, U. Schneider, S. Curtis, D. Bolvin, A. Gruber, J. Susskind, and P. Arkin, 2003: The version 2 Global Precipitation Climatology Project (GPCP) monthly precipitation analysis (1979-present). J. Hydrometeor, 4, 1147-1167.

Bretherton, C. S., M. E. Peters, and L. E. Back, 2004: Relationship between water vapor and precipitation over the tropical oceans. J. Climate. (Accepted)

Chiang, J. C. H., S. E. Zebiak, and M. A. Cane, 2001: Relative roles of elevated heating and surface temperature gradients in driving anomalous surface winds over tropical oceans. J. Atmos. Sci., 58, 1371-1394.

Fu, R., A. D. Del Genio, and W. B. Rossow, 1990: Behavior of deep convective clouds in the tropical Pacific deduced from ISCCP radiance. J. Climate, 3, 1129-1152.

Gadgil, S., P. V. Joseph, and N. V. Joshi, 1984: Ocean-atmosphere coupling over monsoon regions. Nature, 312, 141-143.

Gill, A. E., 1980: Some simple solutions for heat-induced tropical circulation. Quart. J. Roy. Meteor. Soc., 106. 447-462.

Graham, N., and T. P. Barnett, 1987: Observations of sea surface temperature and convection over tropical oceans. Science, 238, 657-659.

Hack, J. J., W. H. Schubert, D. E. Stevens, and H. Kuo, 1989: Response of the Hadley circulation to convective forcing in the ITCZ. J. Atmos. Sci., 46, 2957-2973.

Halpern, D., and C.-W. Hung, 2001: Satellite observations of the southeast Pacific intertropical convergence zone during 1993-1998. J. Geophys. Res., 106, 28107-28112.

Hayes, S. P., M. J. McPhaden, and J. M. Wallace, 1989: The influence of sea-surface temperature on surface wind in the eastern equatorial Pacific: Weekly to monthly 
variability. J. Climate, 2, 1500-1506.

Hubert, L. F., A. F. Krueger, and J. S. Winston, 1969: The double Intertropical Convergence Zone - Fact or fiction? J. Atmos. Sci., 26, 771-773.

Johnson, R. H., T. M. Rickenbach, S. A. Rutledge, P. E. Ciesielski, and W. H. Schubert, 1999: Trimodal characteristics of tropical convection. J. Climate, 12, 2397-2418.

Kalnay, E., and Coauthors, 1996: The NCEP/NCAR 40-year reanalysis project. Bull. Amer. Meteor. Soc., 77, 437-471.

Kessler, W. S., L. M. Rothstein, and D. Chen, 1998: The annual cycle of SST in the eastern tropical Pacific, diagnosed in an ocean GCM. J. Climate, 11, 777-799.

Li, T., and S. G. Philander, 1996: On the annual cycle of the eastern equatorial Pacific. $J$. Climate, 9, 2986-2998.

Lietzke, C. E., C. Deser, and T. H. Vonder Haar, 2001: Evolutionary structure of the eastern Pacific double ITCZ based on satellite moisture profile retrievals. J. Climate, 14, 743-751.

Lindzen, R. S., and S. Nigam, 1987: On the role of sea surface temperature gradients in forcing low-level winds and convergence in the Tropics. J. Atmos. Sci., 44, 2418-2436.

Liu, W. T., W. Tang, and P. S. Polito, 1998: NASA Scatterometer provides global oceansurface wind fields with more structures than numerical weather prediction. Geophys. Res. Lett., 25, 761-764.

Liu, W. T., and X. Xie, 2002: Double intertropical convergence zone-a new look using scatterometer. Geophys. Res. Lett., 29, 222072, doi:10.1029/2002GL015431.

Mechoso, C. R., and Coauthors, 1995: The seasonal cycle over the tropical Pacific in coupled oceao-atmosphere general circulation models. Mon. Wea. Rev., 123, 2825-2838.

Mitchell, T. P., and J. M. Wallace, 1992: The annual cycle in equatorial convection and sea surface temperature. J. Climate, 5, 1140-1156.

Neelin, J. D., 1989: On the interpretation of the Gill model. J. Atmos. Sci., 46, 2466-2468.

Philander, S. G. H., and Coauthors, 1996: Why the ITCZ is mostly north of the equator? J. Climate, 9, 2958-2972. 
Reynolds, R. W., N. A. Rayner, T. M. Smith, D. C. Stokes and W. Wang, 2002: An improved in situ and satellite SST analysis for climate. J. Climate, 15, 1609-1625.

Sobel, A. H., I. M. Held, and C. S. Bretherton, 2002: The ENSO signal in tropical tropospheric temperature. J. Climate, 15, 2702-2706.

$\mathrm{Su}, \mathrm{H}$., and J. D. Neelin, 2003: The scatter in tropical average precipitation anomalies. $J$. Climate, 16, 3966-3977.

Tomas, R. A., and P. J. Webster, 1997: The role of inertial instability in determining the location and strength of near-equatorial convection. Quart. J. Roy. Meteor. Soc., 123, 1445-1482.

Wallace, J. M., T. P. Mitchell, and C. Deser, 1989: The influence of sea-surface temperature on surface wind in the eastern equatorial Pacific: Seasonal and interannual variability. J. Climate, 2, 1492-1499.

Zhang, C., 2001: Double ITCZs. J. Geophys. Res., 106, 11785-11792.

Zhang, C., M. McGauley, and N.A. Bond, 2004: Shallow meridional ciruclation in the tropical eastern Pacific. J. Climate, 17, 133-139.

Zheng, Q., X.-H. Yan, W. T. Liu, W. Tang, and D. Kurz, 1997: Seasonal and interannual variability of atmospheric convergence zones in the tropical Pacific observed with ERS1 scatterometer. Geophys. Res. Lett., 24, 3, 261-263. 


\section{List of Tables}

1 The criterions used to define the ITCZ types during March-April. The unit of $P_{e q}, P_{n}$ and $P_{s}$ is $m m d a y^{-1} \ldots \ldots \ldots \ldots \ldots$

2 The years categorized by the ITCZ types during March-April . . . . . . . 26 


\section{List of Figures}

1 Monthly mean TRMM rainfall ( $m m d a y^{-1}$; shades) and TMI SST ( ${ }^{\circ} C$; contours) in the tropical Pacific ocean during boreal spring. . . . . . . . . 27

2 Meridional profiles of monthly TRMM rainfall $\left[P\left(m m d a y^{-1}\right)\right.$; solid lines; $\left.90.5^{\circ} \mathrm{W}-130.5^{\circ} \mathrm{W}\right]$, surface pressure $\left[\operatorname{sl} p(h P a)\right.$; dashed lines; $90^{\circ} \mathrm{W}-130^{\circ} \mathrm{W}$, and TMI SST $\left({ }^{\circ} \mathrm{C}\right.$; dashdot lines; $\left.90.125^{\circ} \mathrm{W}-130.125^{\circ} \mathrm{W}\right)$ in March. . . . . 28

3 Same as in Figure 2 but in April. . . . . . . . . . . . . . . . 29

4 (a) and (b) $P_{N}+P_{S}$ vs. $\left|P_{N}-P_{S}\right| . P_{N}$ and $P_{S}$ are domain-mean monthly rainfall in March and April. $P_{N}$ is averaged between $0.5^{\circ} \mathrm{N}-14.5^{\circ} \mathrm{N}, 90.5^{\circ} \mathrm{W}-$ $130.5^{\circ} \mathrm{W}$ for TRMM precipitation, and between $1.25^{\circ} \mathrm{N}-13.75^{\circ} \mathrm{N}, 91.125^{\circ} \mathrm{W}-$ $131.125^{\circ} \mathrm{W}$ for GPCP precipitation; $P_{S}$ is averaged between $0.5^{\circ} \mathrm{S}-14.5^{\circ} \mathrm{S}$, $90.5^{\circ} \mathrm{W}-130.5^{\circ} \mathrm{W}$ for TRMM precipitation, and between $1.25^{\circ} \mathrm{S}-13.75^{\circ} \mathrm{S}$, $91.125^{\circ} \mathrm{W}-131.125^{\circ} \mathrm{W}$ for GPCP precipitation. (c) and (d) $S S T_{N}+S S T_{S}$ vs. $\left|S S T_{N}-S S T_{S}\right| . S S T_{N}$ and $S S T_{S}$ are domain-mean SST in March and April. $S S T_{N}$ is averaged between $0.125^{\circ} \mathrm{N}-15.125^{\circ} \mathrm{N}, 90.125^{\circ} \mathrm{W}-130.125^{\circ} \mathrm{W}$ for TMI SST, and between $0.5^{\circ} \mathrm{N}-14.5^{\circ} \mathrm{N}, 91.125^{\circ} \mathrm{W}-131.125^{\circ} \mathrm{W}$ for Reynolds $\mathrm{SST} ; S S T_{S}$ is averaged between $0.125^{\circ} S-15.125^{\circ} S, 90.125^{\circ} \mathrm{W}-130.125^{\circ} \mathrm{W}$ for TMI SST, and between $0.5^{\circ} S-14.5^{\circ} S, 91.125^{\circ} \mathrm{W}-131.125^{\circ} \mathrm{W}$ for Reynolds SST. Dots are for the non-El Niño years, and crosses the El Niño years. The linear trends are only for the non-El Niño years. The units of precipitation and SST are $m m d^{2} a y^{-1}$ and ${ }^{\circ} C$, respectively. . . . . . . . . . . 30

5 (a) TRMM precipitation $\left(m m d a y^{-1}\right)$ vs. TMI SST $\left({ }^{\circ} C\right)$, (b) TRMM precipitation $\left(m m d a y^{-1}\right)$ vs. Reynolds SST $\left({ }^{\circ} \mathrm{C}\right)$, (c) TRMM precipitation $(\mathrm{mm}$ $\left.d a y^{-1}\right)$ vs. QuikScat surface convergence $\left(10^{-5} s^{-1}\right)$, and (d) QuikScat surface convergence $\left(10^{-5} s^{-1}\right)$ vs. TMI SST $\left({ }^{\circ} C\right)$ at $5^{\circ} S$ (crosses), $0^{\circ}$ (stars) and $5^{\circ} N$ (dots) during March-April. (a) and (b) is from 1998-2003; (c) and (d) $2000-2003 \ldots \ldots \ldots \ldots \ldots \ldots \ldots$ 
6 Meridional profiles of monthly TRMM rainfall $\left[P\left(m m d a y^{-1}\right)\right.$; solid lines; $90.5^{\circ} \mathrm{W}-130.5^{\circ} \mathrm{W}$, TMI cloud liquid water $\left(2 \times 10^{-2} \mathrm{~mm}\right.$; dashdot lines; $90.125^{\circ} \mathrm{W}-130.125^{\circ} \mathrm{W}$ ), and TMI columnar water vapor ( $\mathrm{mm}$; dashed lines; $\left.90.125^{\circ} \mathrm{W}-130.125^{\circ} \mathrm{W}\right)$ in March. ................. 32

7 Same as in Figure 6 but in April. . . . . . . . . . . . . . 33

8 Meridional profiles of monthly TRMM rainfall [ $P\left(m m d a y^{-1}\right)$; solid lines; $\left.90.5^{\circ} W-130.5^{\circ} W\right]$ and QuikScat surface convergence $\left[C V \approx-\frac{\partial v}{\partial y}\left(10^{-5} s^{-1}\right)\right.$; dashed lines; $90.125^{\circ} \mathrm{W}-130.125^{\circ} \mathrm{W}$ ) in March (left panel) and April (right

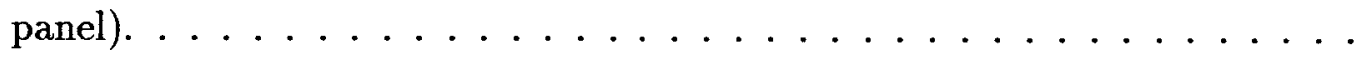

9 Meridional profiles of monthly TMI SST ( ${ }^{\circ} \mathrm{C}$; solid lines) and QuikScat meridional wind component $\left(\mathrm{ms}^{-1}\right.$; dashed lines) between $90.125^{\circ} \mathrm{W}-130.125^{\circ} \mathrm{W}$ in March (left panel) and April (right panel). . . . . . . . . . . . . .

10 Latitude-time diagram of weekly TRMM rainfall $\left[\mathrm{mm} \mathrm{day^{-1 }}\right.$; shades; $90.5^{\circ} \mathrm{W}-$ $\left.130.5^{\circ} \mathrm{W}\right]$ and TMI SST $\left({ }^{\circ} \mathrm{C}\right.$; contours; $\left.90.125^{\circ} \mathrm{W}-130.125^{\circ} \mathrm{W}\right)$. Thin solid, dashed and thick dashed vertical lines denote March 1, April 1, and May 1,

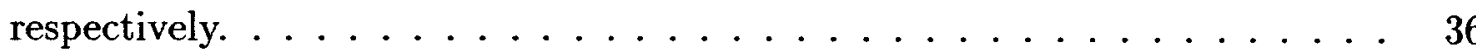

11 Latitude-time diagram of weekly mean QuikScat surface convergence $[C V \approx$ $-\frac{\partial v}{\partial y}\left(10^{-5} s^{-1}\right)$; color shades; $\left.90.125^{\circ} W-130.125^{\circ} W\right)$ and TRMM rainfall $\left[m m \mathrm{day}^{-1}\right.$; contours; $\left.90.5^{\circ} \mathrm{W}-130.5^{\circ} \mathrm{W}\right] . \ldots \ldots \ldots$

12 Latitude-time diagram of weekly TRMM rainfall $\left[\mathrm{mm} \mathrm{day}^{-1}\right.$; contours; $90.5^{\circ} \mathrm{W}$ $\left.130.5^{\circ} \mathrm{W}\right]$ and TMI cloud liquid water $\left(\mathrm{mm}\right.$; shades; $\left.90.125^{\circ} \mathrm{W}-130.125^{\circ} \mathrm{W}\right) . \quad 38$

13 Latitude-time diagram of weekly TRMM rainfall $\left[\mathrm{mm} \mathrm{day^{-1 }}\right.$; contours; $90.5^{\circ} \mathrm{W}$ $\left.130.5^{\circ} \mathrm{W}\right]$ and TMI columnar water vapor ( $\mathrm{mm}$; shades; $\left.90.125^{\circ} \mathrm{W}-130.125^{\circ} \mathrm{W}\right) .39$

14 Meridional profiles of monthly rainfall from GPCP (solid lines) and NCEP/NCAR reanalysis project (dashed lines) $\left[P\left(m m d^{-1}\right) ; 91.125^{\circ} \mathrm{W}-131.125^{\circ} \mathrm{W}\right] \mathrm{dur}-$ ing 1979-2003. Dots denote monthly GPCP rainfall in each year. . . . . . . . 
15 Composite meridional profiles of monthly (a) GPCP rainfall $\left(m m d a y^{-1}\right)$ and (b) Reynolds SST $\left({ }^{\circ} \mathrm{C}\right.$ ) between $91.125^{\circ} \mathrm{W}-131.125^{\circ} \mathrm{W}$ for the four ITCZ types during March-April. Solid lines are for Type I, dashed ones for Type II, dashdot ones for Type III, and dotted ones for Type IV . . . . . . . . . 41

16 Composite horizontal distributions of monthly GPCP rainfall $\left(\mathrm{mm} \mathrm{day}^{-1}\right.$; shades) and Reynolds SST ( ${ }^{\circ} C$; contours) for the four ITCZ types during March-April. . . . . . . . . . . . . . . . . . . . 
Table 1: The criterions used to define the ITCZ types during March-April. The unit of $P_{e q}$, $P_{n}$ and $P_{s}$ is $m m d a y^{-1}$.

\begin{tabular}{l|c}
\hline \hline $\begin{array}{l}\text { Type I } \\
\text { (Double ITCZ) }\end{array}$ & $\begin{array}{c}\text { (i) } P_{e q}<3, \text { (ii) } P_{s}, P_{n} \geq 3 \\
\text { or } 2 \leq P_{n}, P_{s} \leq 5\end{array}$ \\
\hline $\begin{array}{l}\text { Type II } \\
\text { (El Niño) }\end{array}$ & $P_{e q} \geq 3$ \\
\hline $\begin{array}{l}\text { Type III } \\
\text { (South Dominant) }\end{array}$ & $\begin{array}{c}\text { (i) } P_{e q}<3, \text { (ii) } P_{s} \geq 3, \text { if } P_{n}<2 \\
\text { or } P_{s}>5, \text { if } 3>P_{n} \geq 2\end{array}$ \\
\hline $\begin{array}{l}\text { Type IV } \\
\text { (North Dominant) }\end{array}$ & $\begin{array}{c}\text { (i) } P_{e q}<3,\left(\text { ii) } P_{n} \geq 3, \text { if } P_{s}<2\right. \\
\text { or } P_{n}>5, \text { if } 3>P_{s} \geq 2\end{array}$ \\
\hline \hline
\end{tabular}

Table 2: The years categorized by the ITCZ types during March-April

\begin{tabular}{|c|c|c|}
\hline & March & April \\
\hline Type I & $\begin{array}{c}1979,1982,1984,1986,1988 \\
1990,1993,1994,2001\end{array}$ & $\begin{array}{c}1979,1980,1982,1984,1985 \\
1986,1988,1989,1991,1993 \\
1994,1996,1999,2000,2001 \\
2002\end{array}$ \\
\hline Type II & $\begin{array}{c}1983,1987,1992,1997,1998 \\
2002\end{array}$ & $1983,1987,1992,1998$ \\
\hline Type III & $1985,1989,1996,1999,2000$ & \\
\hline Type IV & $1980,1981,1991,1995,2003$ & $1981,1990,1995,1997,2003$ \\
\hline
\end{tabular}


February

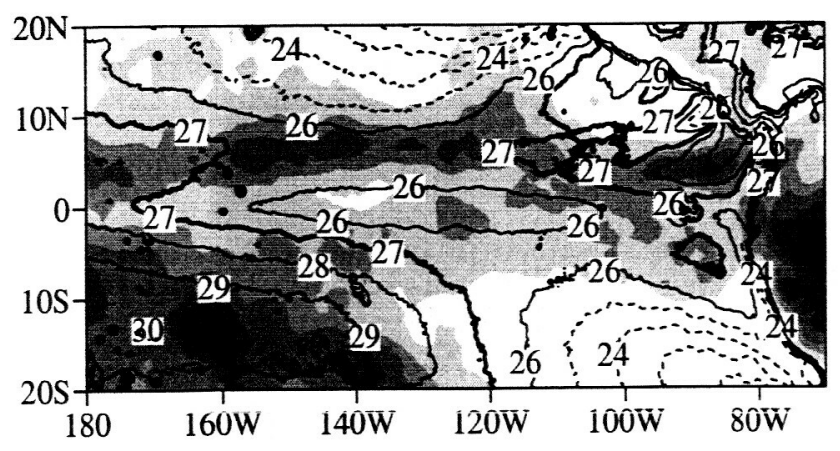

April

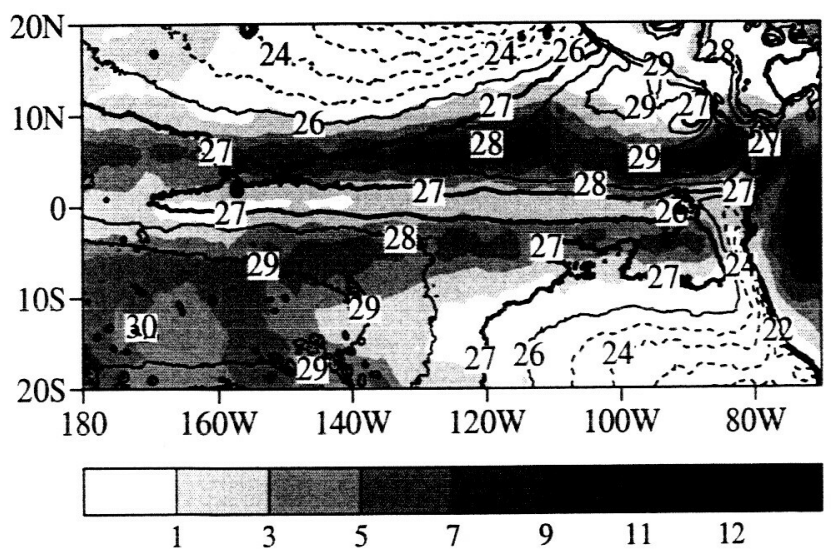

March

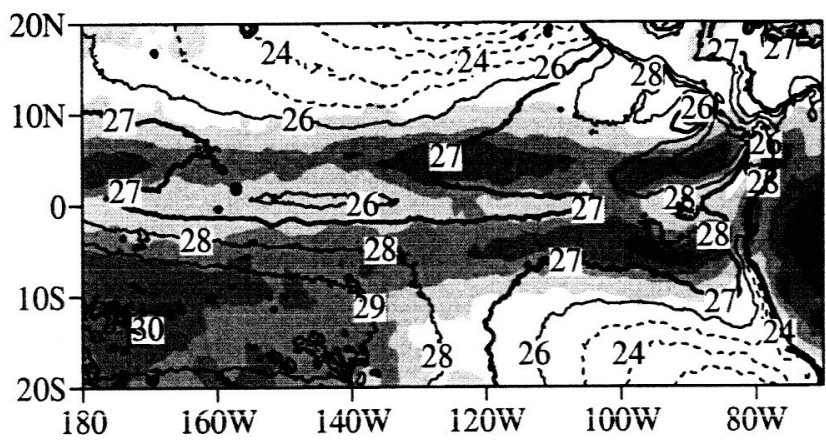

May

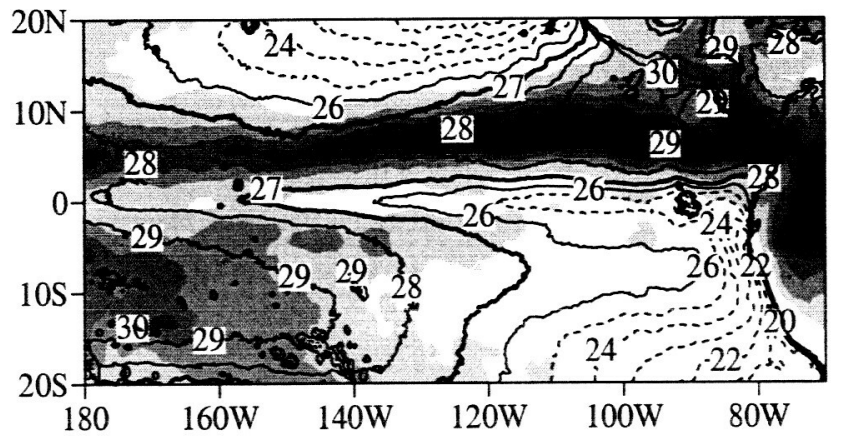

Figure 1: Monthly mean TRMM rainfall ( $m m$ day $^{-1}$; shades) and TMI SST $\left({ }^{\circ} \mathrm{C}\right.$; contours) in the tropical Pacific ocean during boreal spring. 

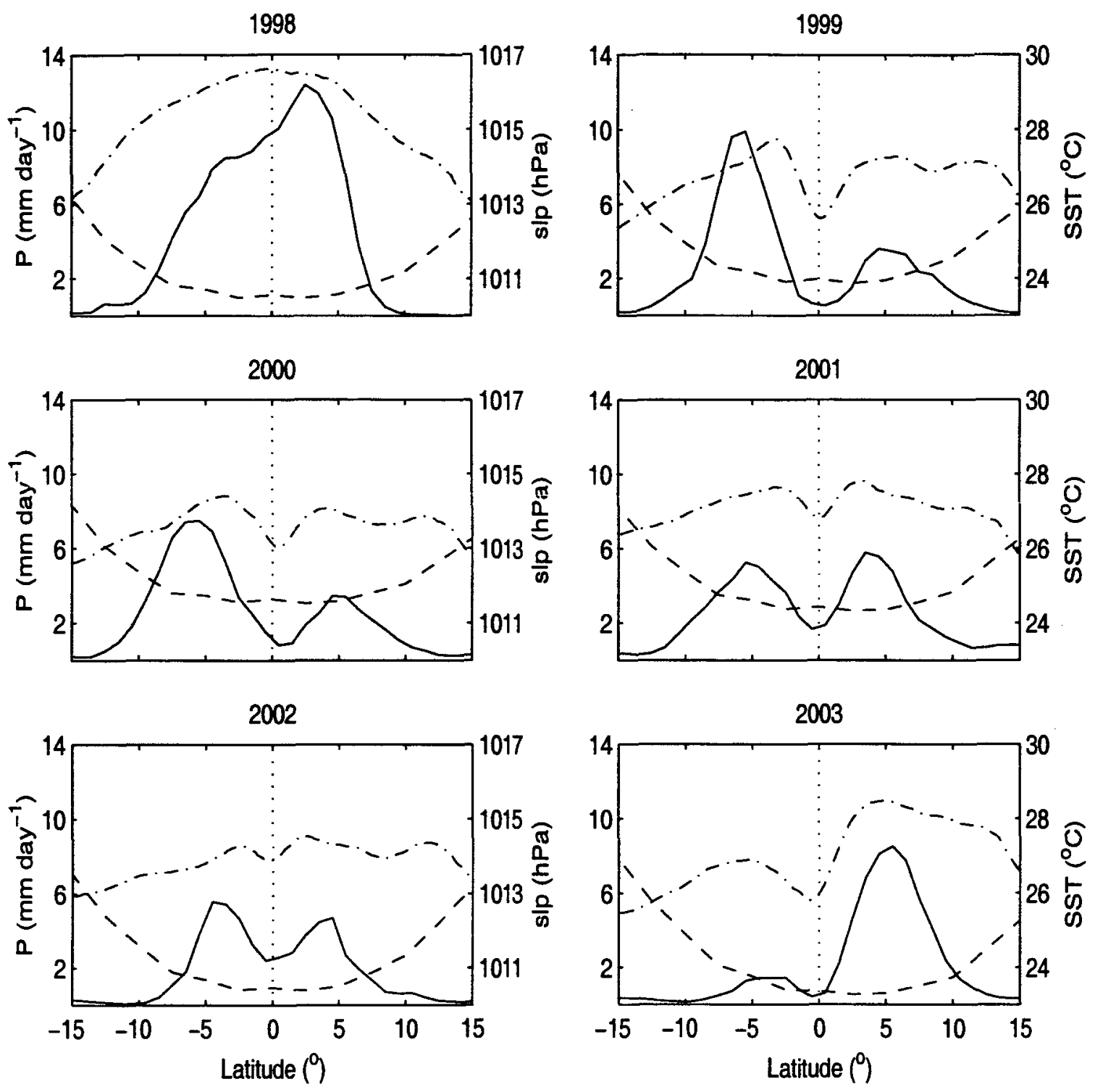

Figure 2: Meridional profiles of monthly TRMM rainfall $\left[P\left(\mathrm{~mm} d a y^{-1}\right)\right.$; solid lines; $90.5^{\circ} \mathrm{W}-130.5^{\circ} \mathrm{W}$ ], surface pressure $\left[s l p(h \mathrm{~Pa})\right.$; dashed lines; $\left.90^{\circ} \mathrm{W}-130^{\circ} \mathrm{W}\right]$, and TMI SST $\left({ }^{\circ} C\right.$; dashdot lines; $\left.90.125^{\circ} \mathrm{W}-130.125^{\circ} \mathrm{W}\right)$ in March. 

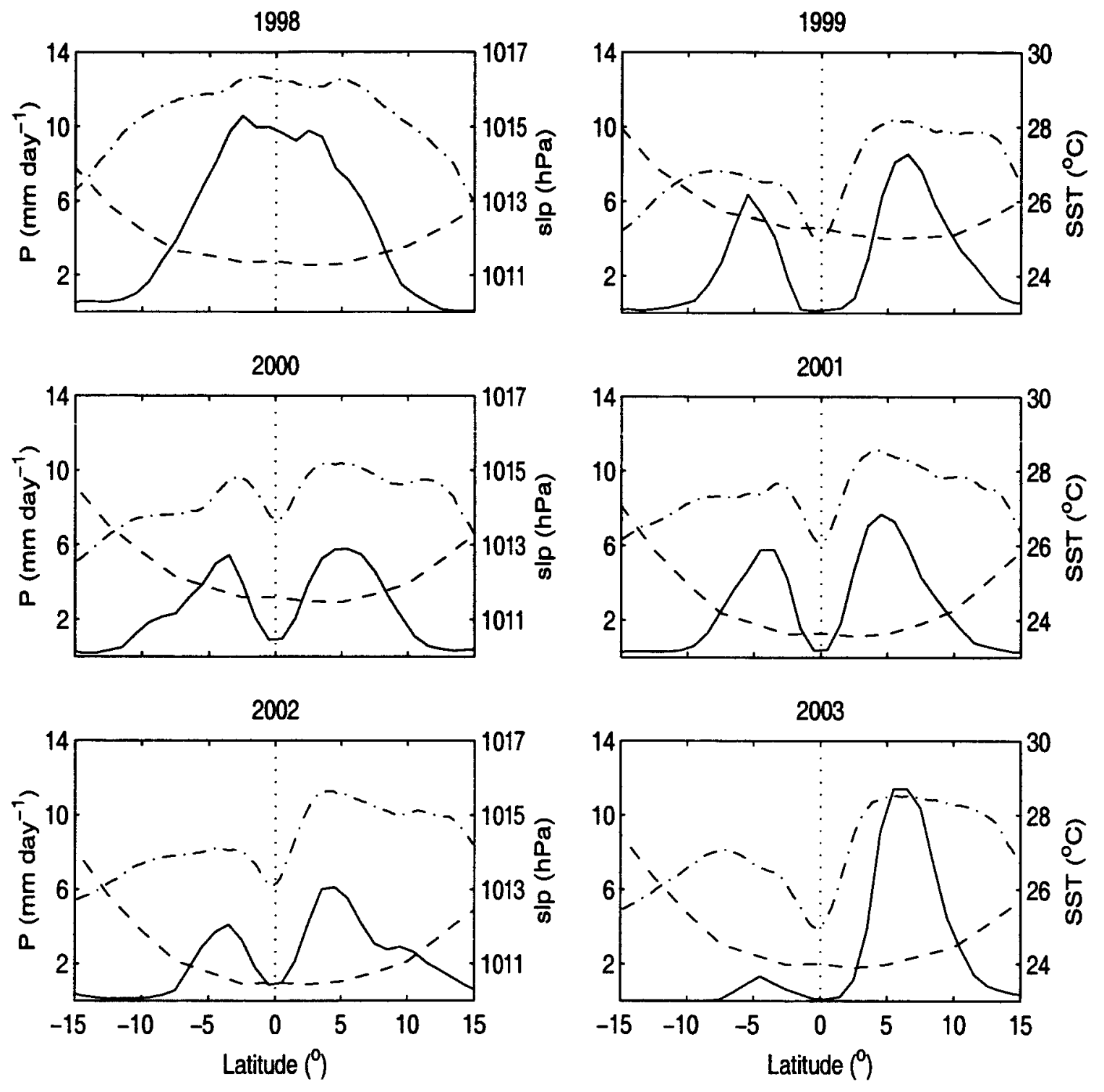

Figure 3: Same as in Figure 2 but in April. 
(a) TRMM Precipitation

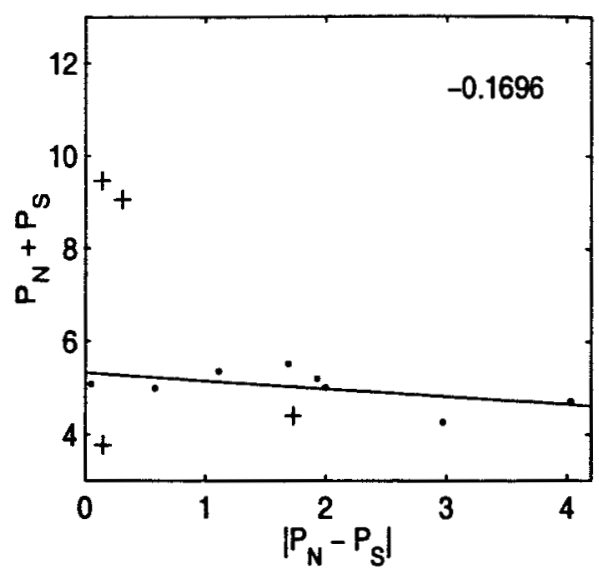

(c) TMI SST

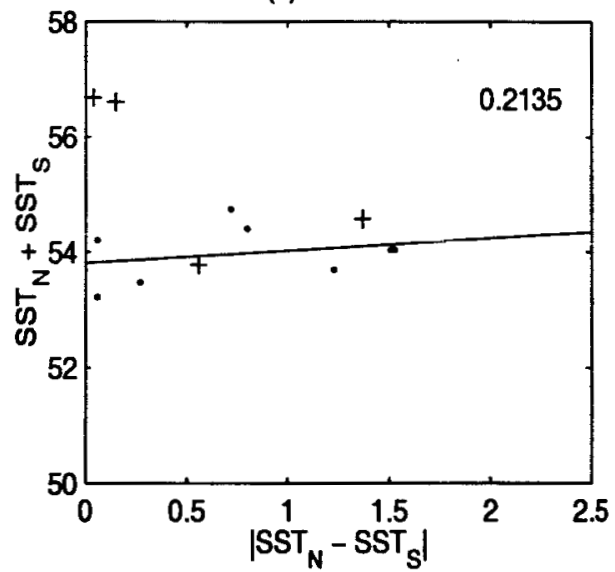

(b) GPCP Precipitation

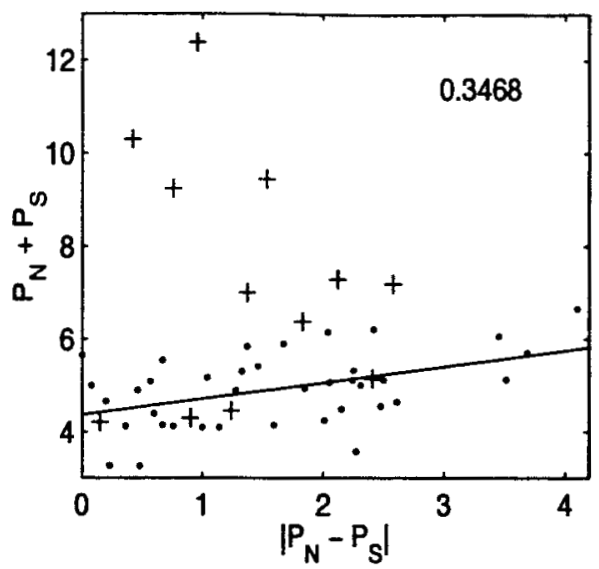

(d) Reynolds SST

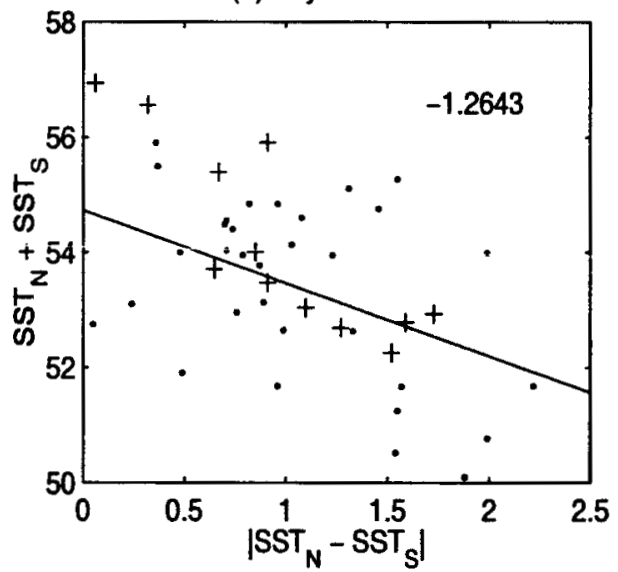

Figure 4: (a) and (b) $P_{N}+P_{S}$ vs. $\left|P_{N}-P_{S}\right| . P_{N}$ and $P_{S}$ are domain-mean monthly rainfall in March and April. $P_{N}$ is averaged between $0.5^{\circ} \mathrm{N}-14.5^{\circ} \mathrm{N}, 90.5^{\circ} \mathrm{W}-130.5^{\circ} \mathrm{W}$ for TRMM precipitation, and between $1.25^{\circ} \mathrm{N}-13.75^{\circ} \mathrm{N}, 91.125^{\circ} \mathrm{W}-131.125^{\circ} \mathrm{W}$ for GPCP precipitation; $P_{S}$ is averaged between $0.5^{\circ} S-14.5^{\circ} \mathrm{S}, 90.5^{\circ} \mathrm{W}-130.5^{\circ} \mathrm{W}$ for TRMM precipitation, and between $1.25^{\circ} \mathrm{S}-13.75^{\circ} \mathrm{S}, 91.125^{\circ} \mathrm{W}-131.125^{\circ} \mathrm{W}$ for GPCP precipitation. (c) and (d) $S S T_{N}+S S T_{S}$ vs. $\left|S S T_{N}-S S T_{S}\right| . S S T_{N}$ and $S S T_{S}$ are domain-mean SST in March and April. $S S T_{N}$ is averaged between $0.125^{\circ} \mathrm{N}-15.125^{\circ} \mathrm{N}, 90.125^{\circ} \mathrm{W}-130.125^{\circ} \mathrm{W}$ for TMI SST, and between $0.5^{\circ} \mathrm{N}-14.5^{\circ} \mathrm{N}, 91.125^{\circ} \mathrm{W}-131.125^{\circ} \mathrm{W}$ for Reynolds SST; $S S T_{S}$ is averaged between $0.125^{\circ} \mathrm{S}-15.125^{\circ} \mathrm{S}, 90.125^{\circ} \mathrm{W}-130.125^{\circ} \mathrm{W}$ for TMI SST, and between $0.5^{\circ} \mathrm{S}-14.5^{\circ} \mathrm{S}, 91.125^{\circ} \mathrm{W}-131.125^{\circ} \mathrm{W}$ for Reynolds SST. Dots are for the non-El Niño years, and crosses the El Niño years. The linear trends are only for the non-El Niño years. The units of precipitation and SST are $m m d a y^{-1}$ and ${ }^{\circ} C$, respectively. 
(a)

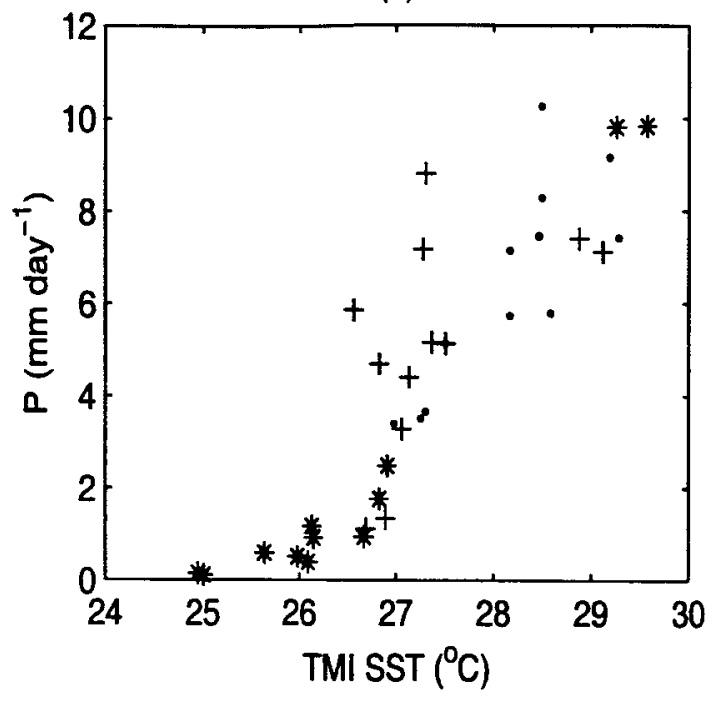

(c)

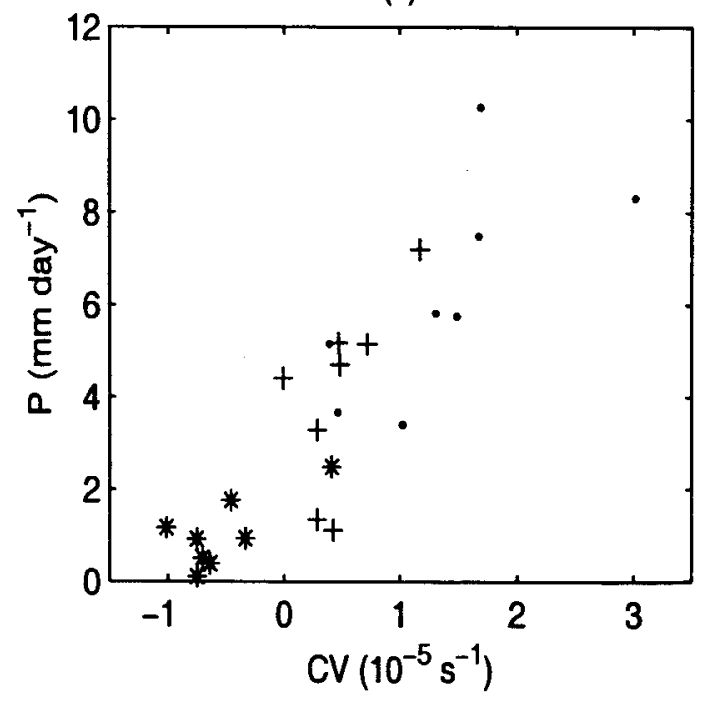

(b)

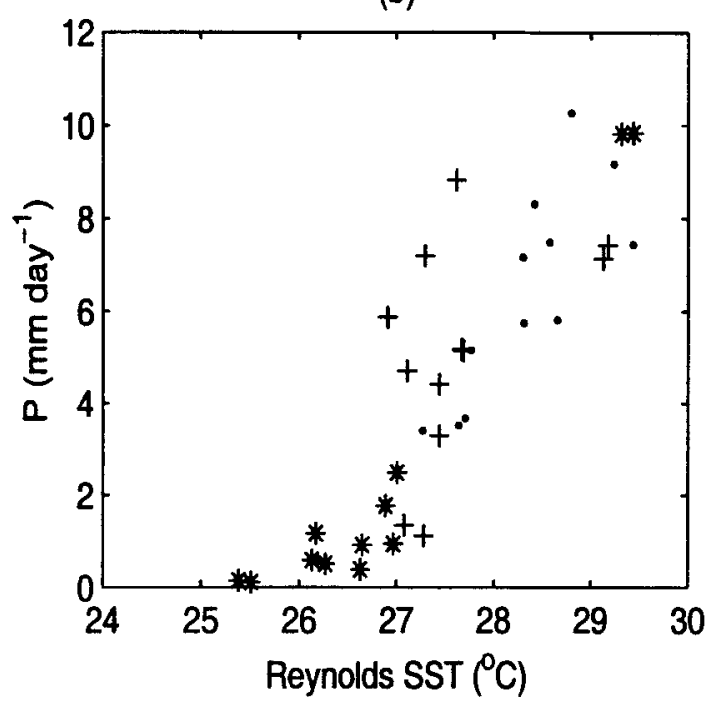

(d)

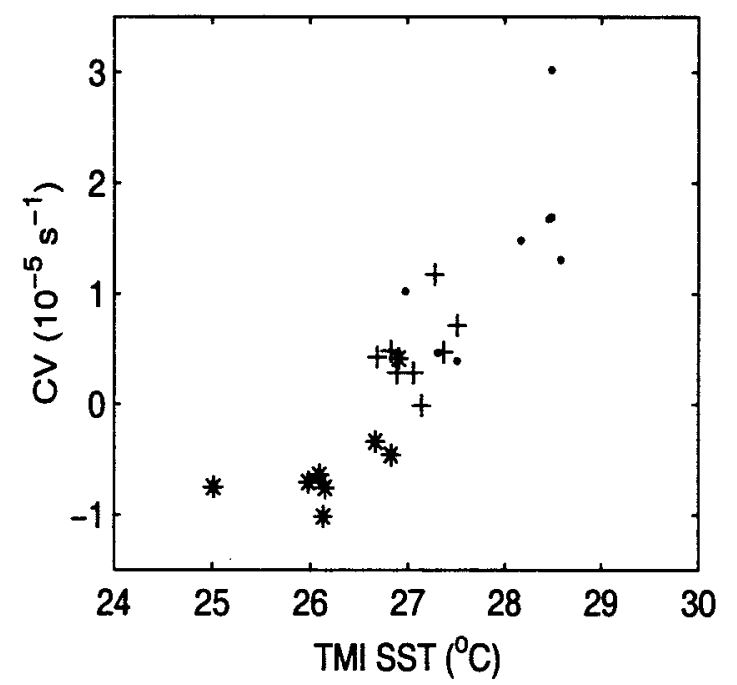

Figure 5: (a) TRMM precipitation $\left(m m d a y^{-1}\right)$ vs. TMI SST $\left({ }^{\circ} C\right)$, (b) TRMM precipitation $\left(m m d a y^{-1}\right)$ vs. Reynolds SST $\left({ }^{\circ} C\right)$, (c) TRMM precipitation $\left(m m d a y^{-1}\right)$ vs. QuikScat surface convergence $\left(10^{-5} s^{-1}\right)$, and (d) QuikScat surface convergence $\left(10^{-5} s^{-1}\right)$ vs. TMI SST $\left({ }^{\circ} \mathrm{C}\right.$ ) at $5^{\circ} S$ (crosses), $0^{\circ}$ (stars) and $5^{\circ} N$ (dots) during March-April. (a) and (b) is from 1998-2003; (c) and (d) 2000-2003. 

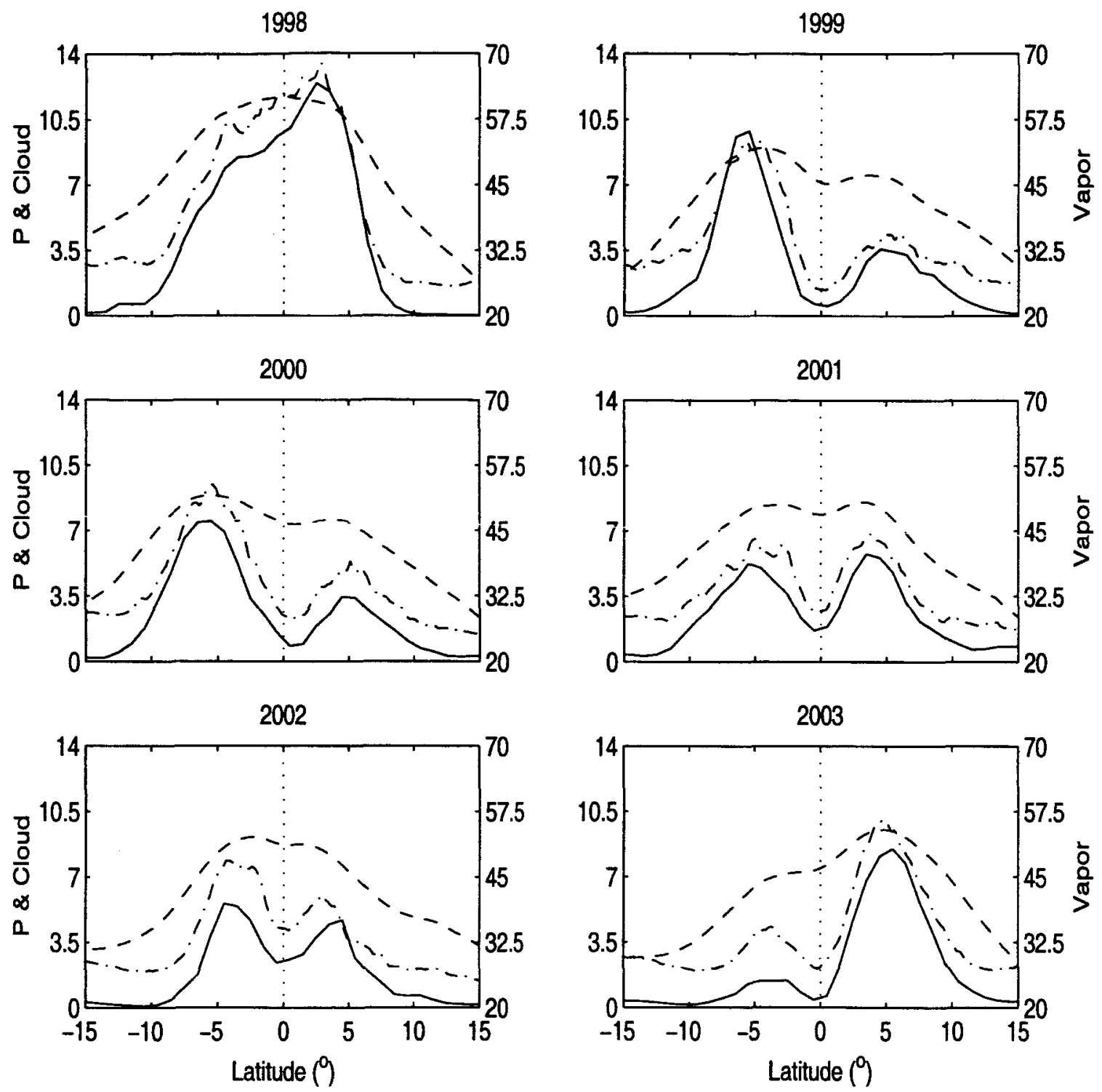

Figure 6: Meridional profiles of monthly TRMM rainfall $\left[P\left(m m d a y^{-1}\right)\right.$; solid lines; $90.5^{\circ} \mathrm{W}-130.5^{\circ} \mathrm{W}$, TMI cloud liquid water $\left(2 \times 10^{-2} \mathrm{~mm}\right.$; dashdot lines; $90.125^{\circ} \mathrm{W}-$ $\left.130.125^{\circ} \mathrm{W}\right)$, and TMI columnar water vapor $\left(\mathrm{mm}\right.$; dashed lines; $\left.90.125^{\circ} \mathrm{W}-130.125^{\circ} \mathrm{W}\right)$ in March. 

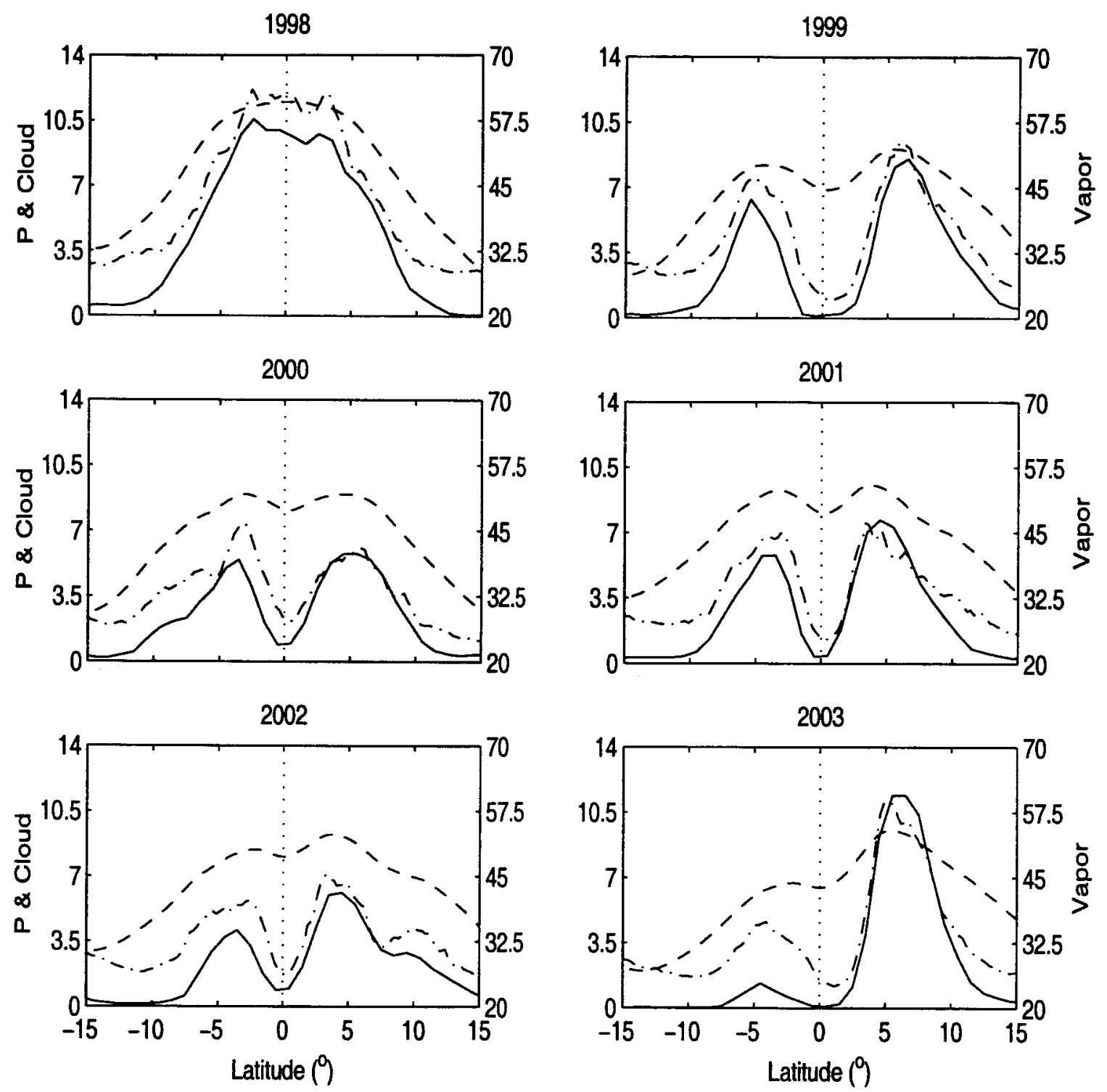

Figure 7: Same as in Figure 6 but in April. 

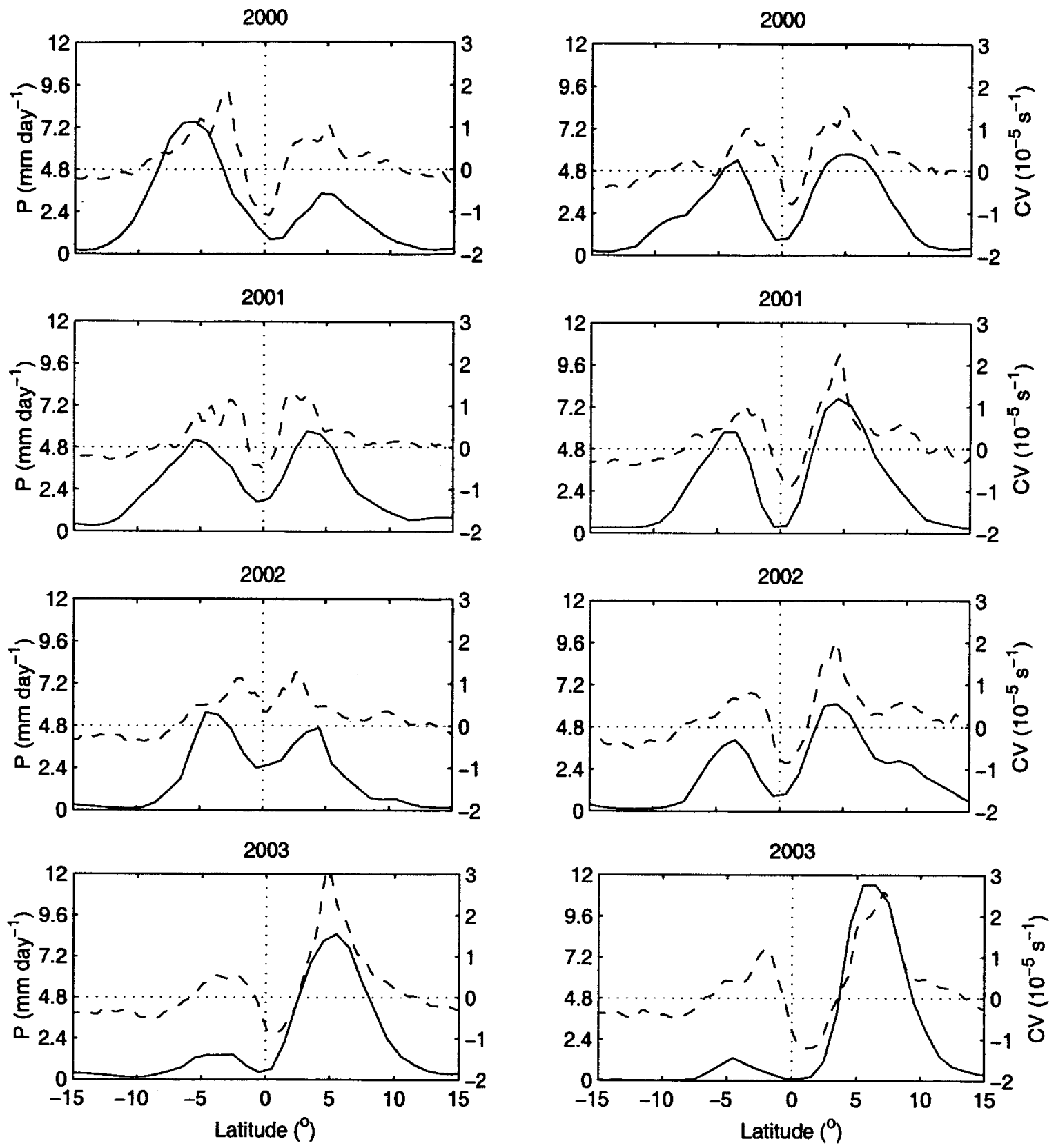

Figure 8: Meridional profiles of monthly TRMM rainfall $\left[P\left(m m d a y^{-1}\right)\right.$; solid lines; $\left.90.5^{\circ} \mathrm{W}-130.5^{\circ} \mathrm{W}\right]$ and QuikScat surface convergence $\left[C V \approx-\frac{\partial v}{\partial y}\left(10^{-5} \mathrm{~s}^{-1}\right)\right.$; dashed lines; $90.125^{\circ} \mathrm{W}-130.125^{\circ} \mathrm{W}$ ) in March (left panel) and April (right panel). 

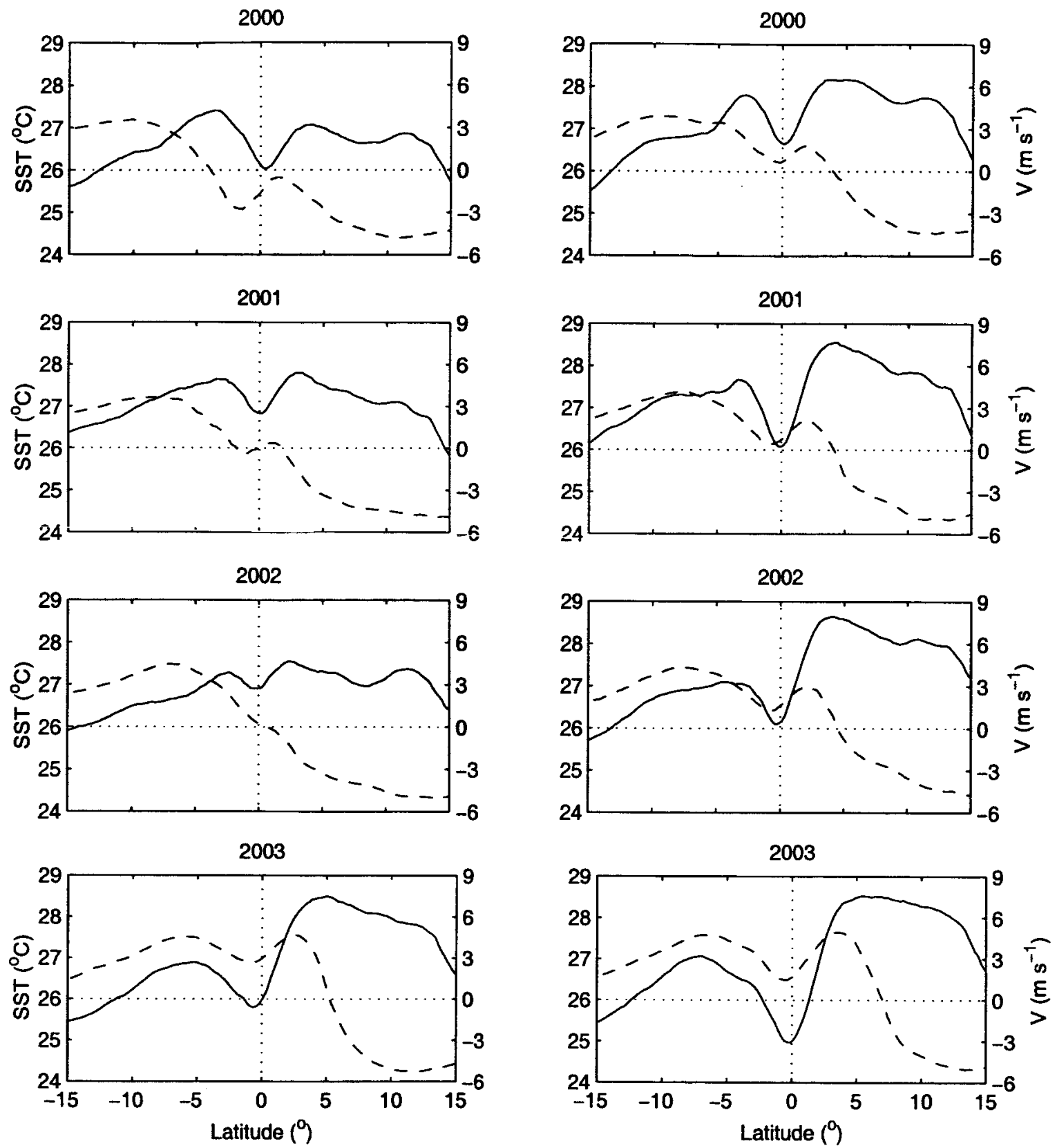

Figure 9: Meridional profiles of monthly TMI SST $\left({ }^{\circ} \mathrm{C}\right.$; solid lines) and QuikScat meridional wind component $\left(\mathrm{ms}^{-1}\right.$; dashed lines) between $90.125^{\circ} \mathrm{W}-130.125^{\circ} \mathrm{W}$ in March (left panel) and April (right panel). 


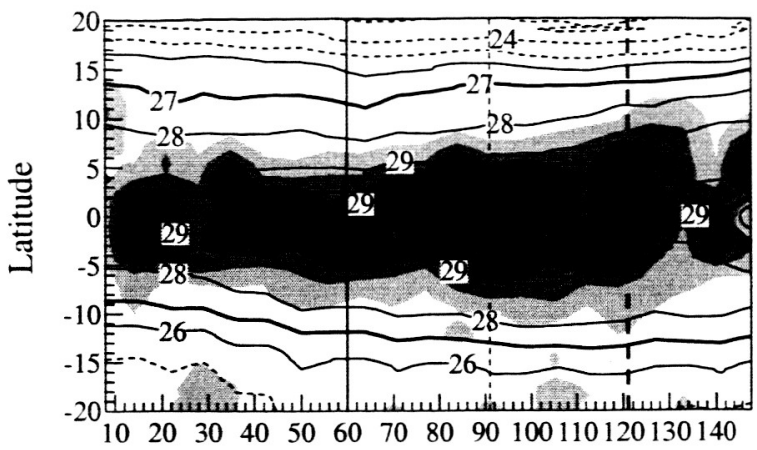

2000

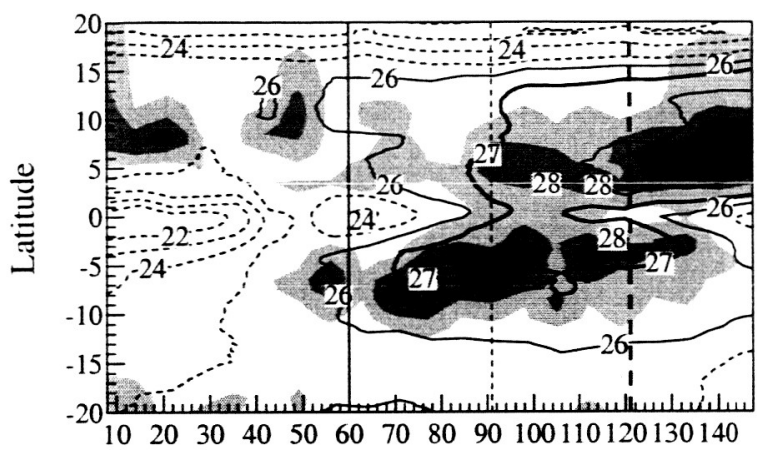

2002

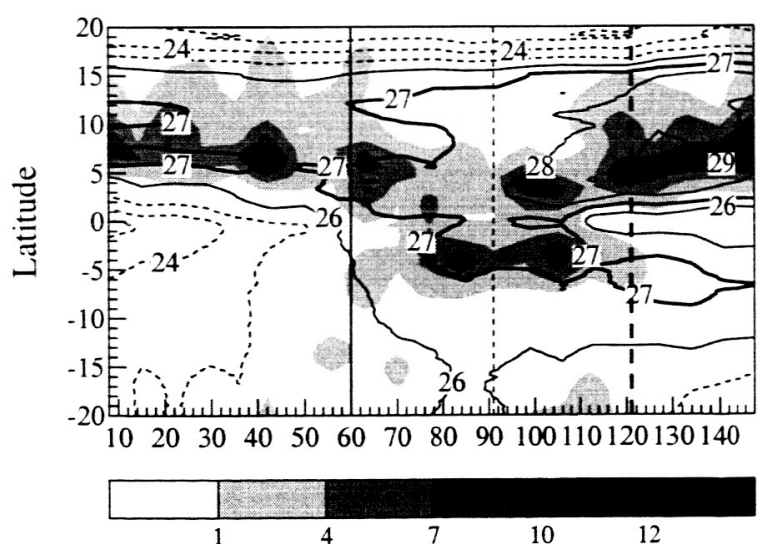

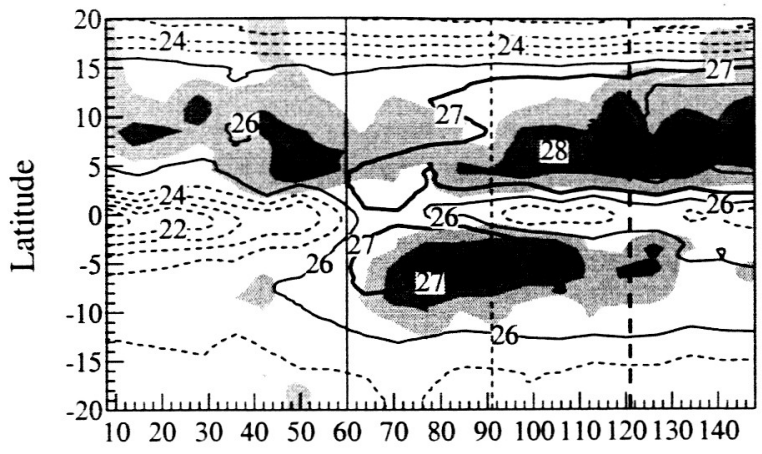

2001

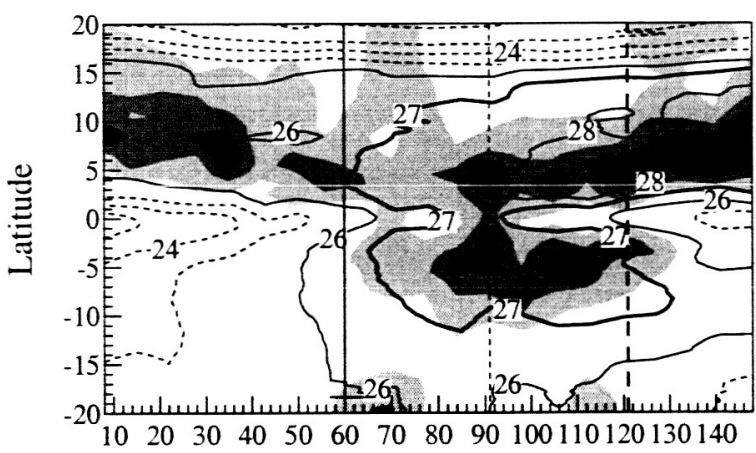

2003

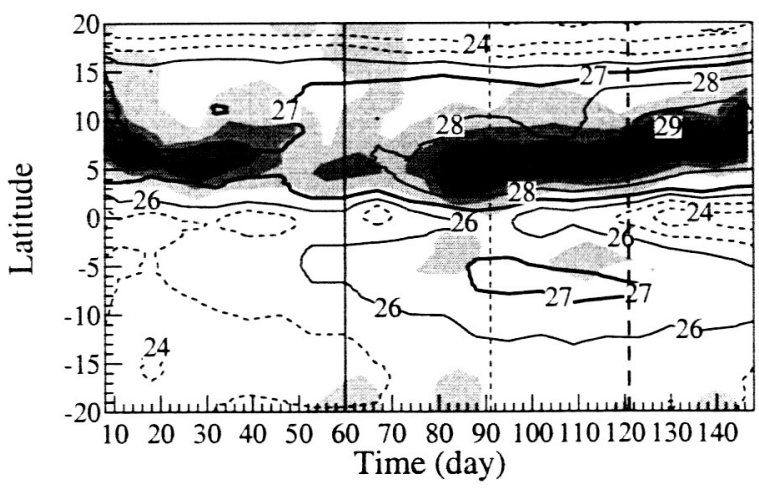

Figure 10: Latitude-time diagram of weekly TRMM rainfall $\left[\mathrm{mm} \mathrm{day}^{-1}\right.$; shades; $90.5^{\circ} \mathrm{W}-$ $\left.130.5^{\circ} \mathrm{W}\right]$ and TMI SST $\left({ }^{\circ} \mathrm{C}\right.$; contours; $\left.90.125^{\circ} \mathrm{W}-130.125^{\circ} \mathrm{W}\right)$. Thin solid, dashed and thick dashed vertical lines denote March 1, April 1, and May 1, respectively. 


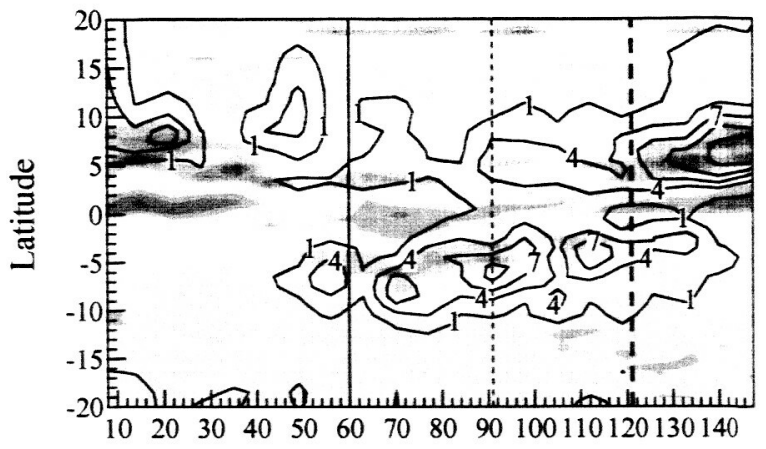

2002

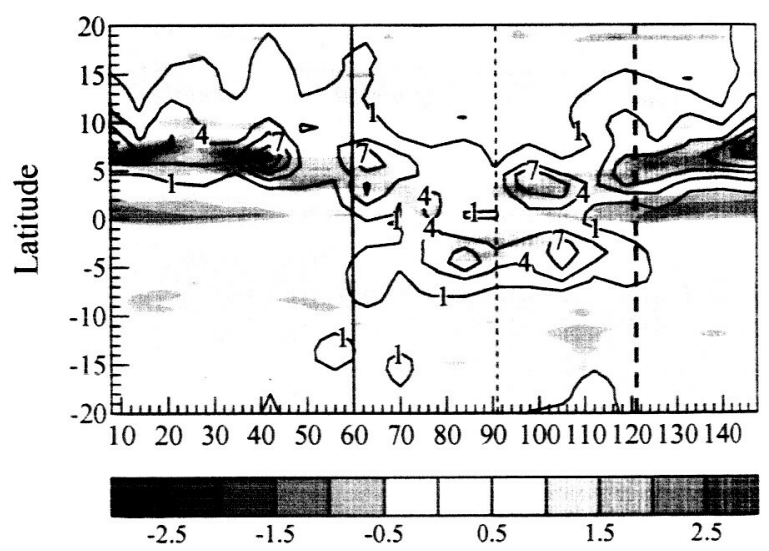

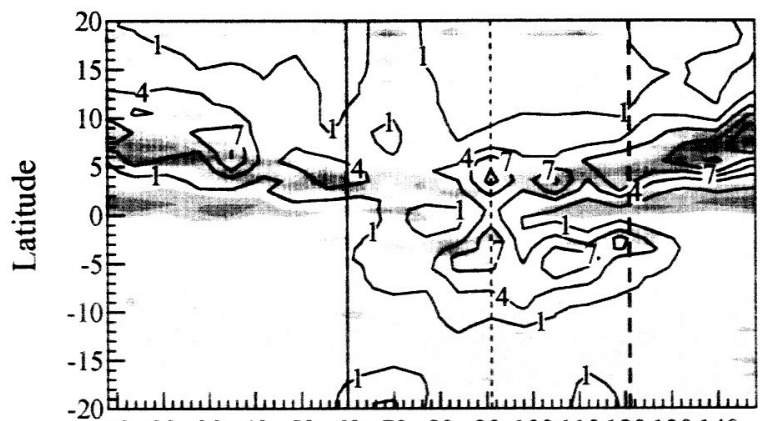

$102030 \quad 40 \quad 5060708090100110120130140$

2003

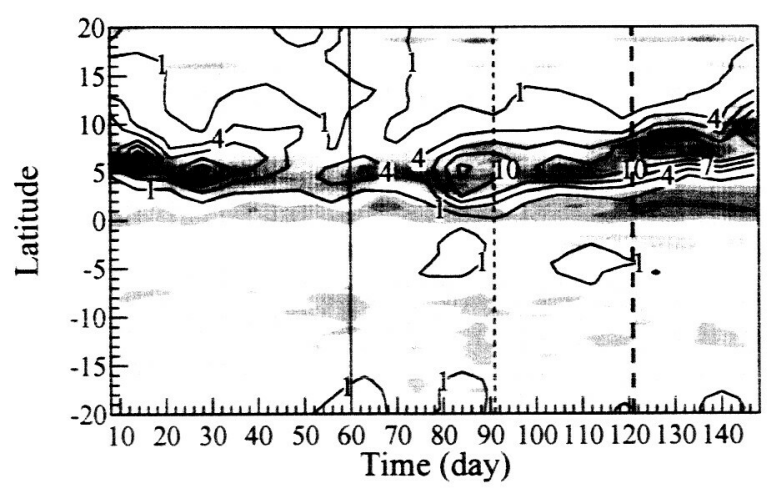

Figure 11: Latitude-time diagram of weekly mean QuikScat surface convergence $\left[C V \approx-\frac{\partial v}{\partial y}\right.$ $\left(10^{-5} \mathrm{~s}^{-1}\right)$; color shades; $\left.90.125^{\circ} \mathrm{W}-130.125^{\circ} \mathrm{W}\right)$ and TRMM rainfall [ $\mathrm{mm} \mathrm{day^{-1 }}$; contours; $\left.90.5^{\circ} \mathrm{W}-130.5^{\circ} \mathrm{W}\right]$. 


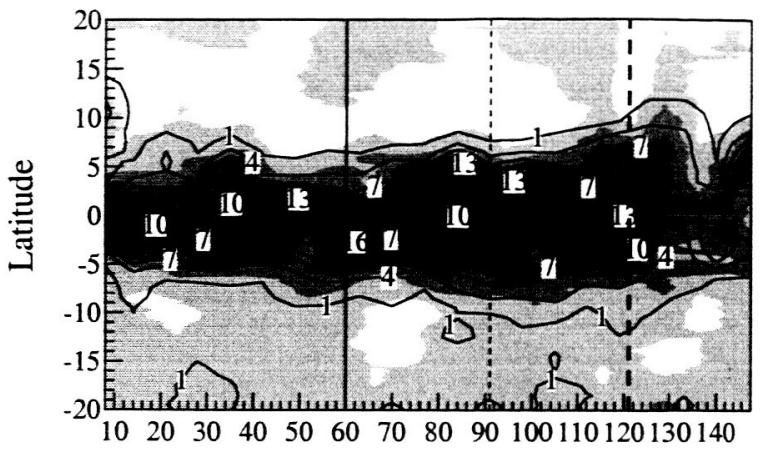

2000

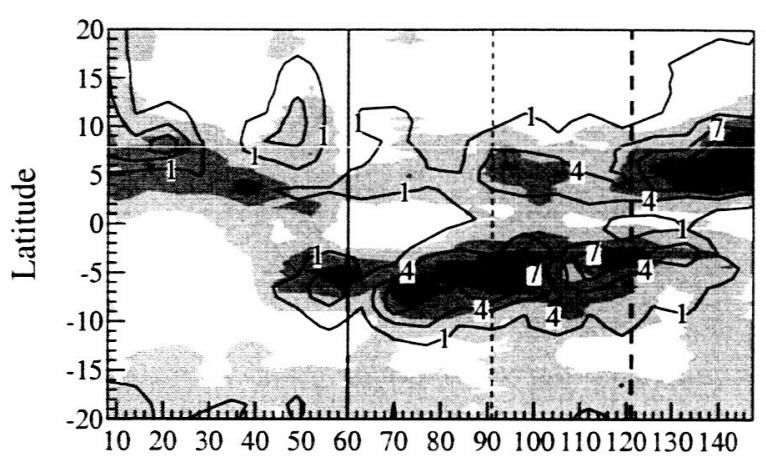

2002

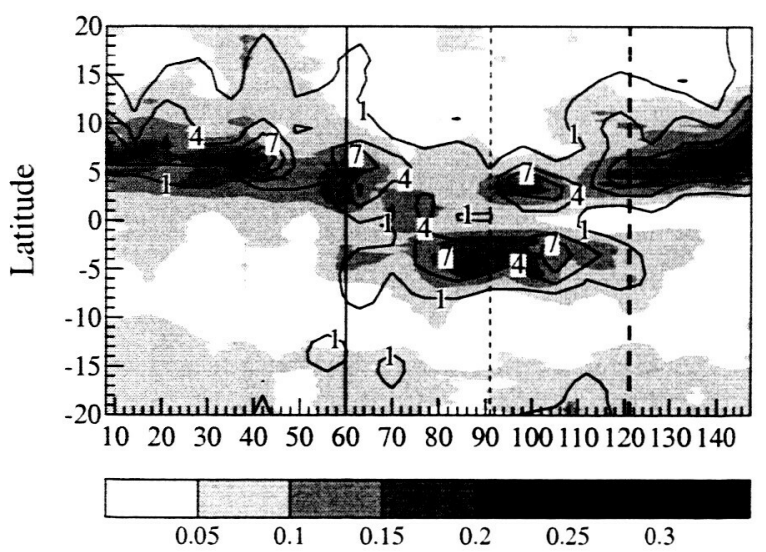

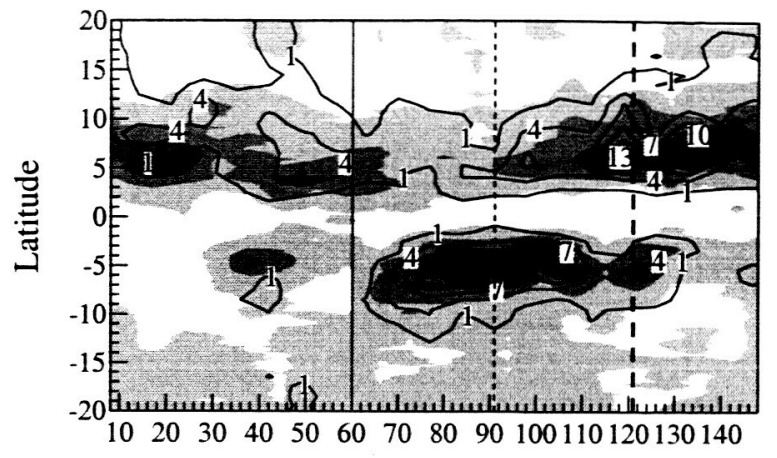

2001

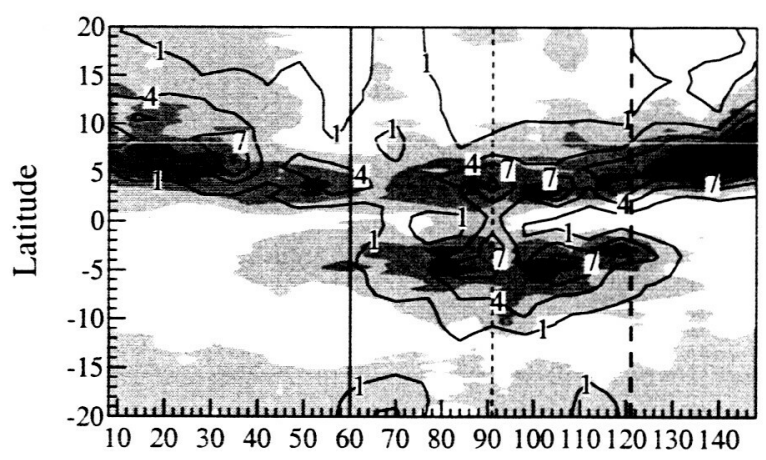

2003

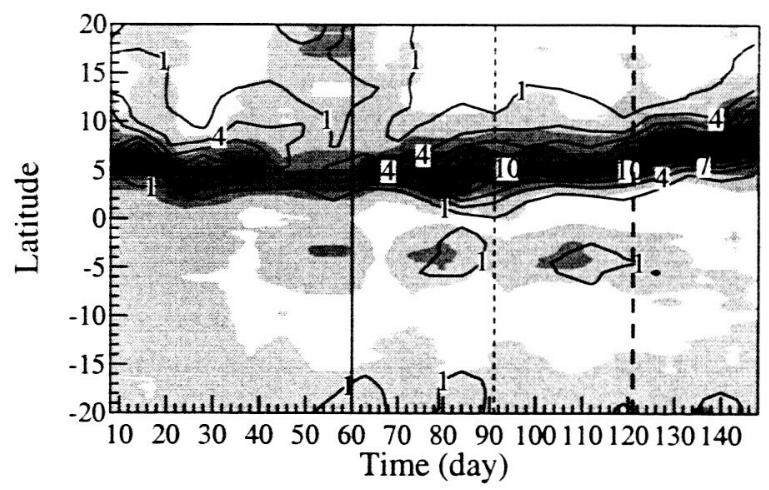

Figure 12: Latitude-time diagram of weekly TRMM rainfall $\left[\mathrm{mm}_{\mathrm{a}} \mathrm{a} \mathrm{y}^{-1}\right.$; contours; $90.5^{\circ} \mathrm{W}-$ $\left.130.5^{\circ} \mathrm{W}\right]$ and TMI cloud liquid water $\left(\mathrm{mm}\right.$; shades; $\left.90.125^{\circ} \mathrm{W}-130.125^{\circ} \mathrm{W}\right)$. 
1998

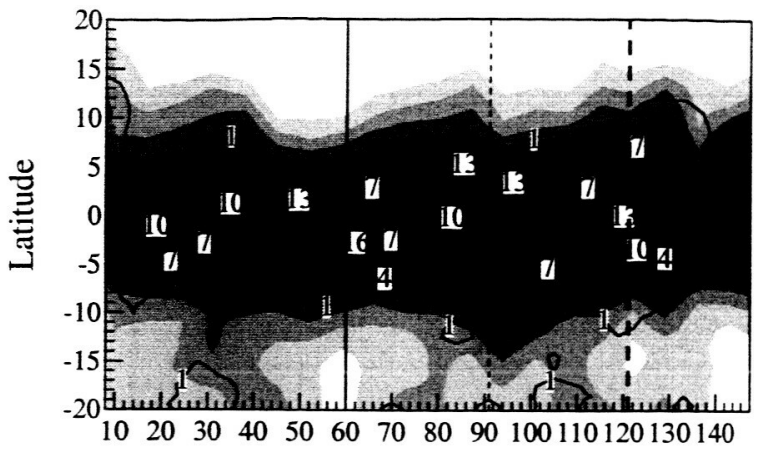

2000

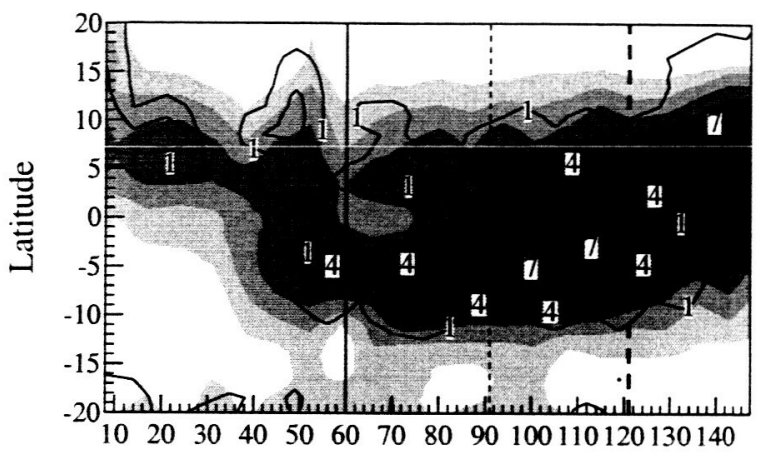

2002

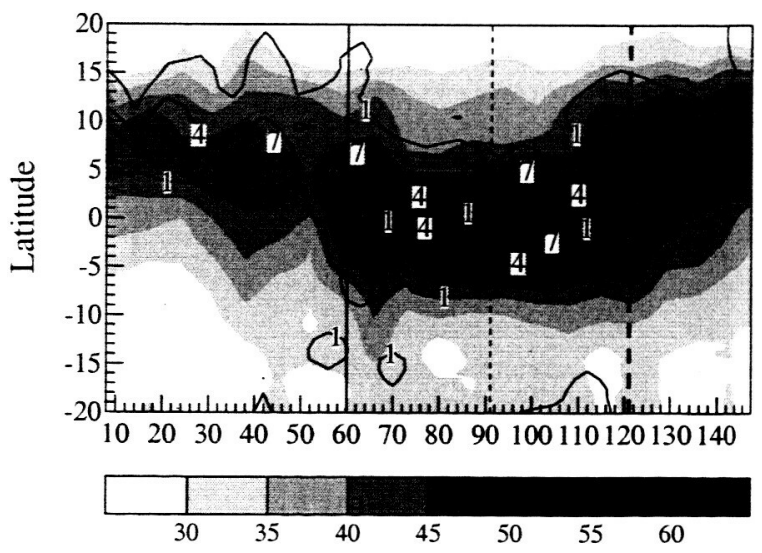

1999
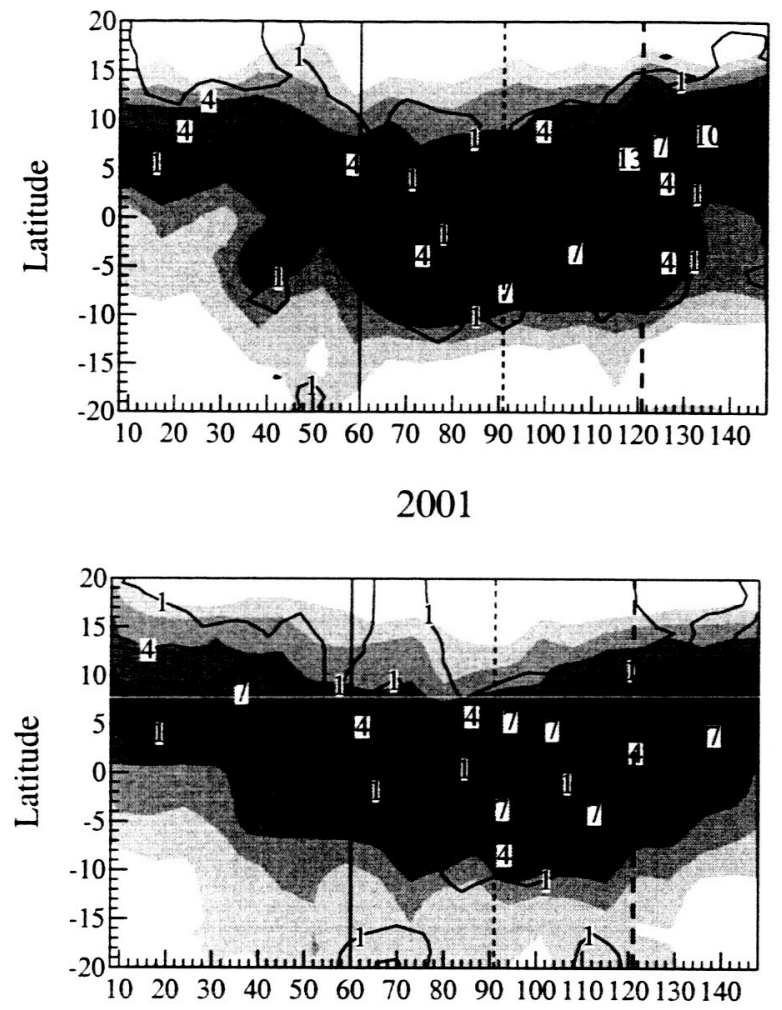

2003

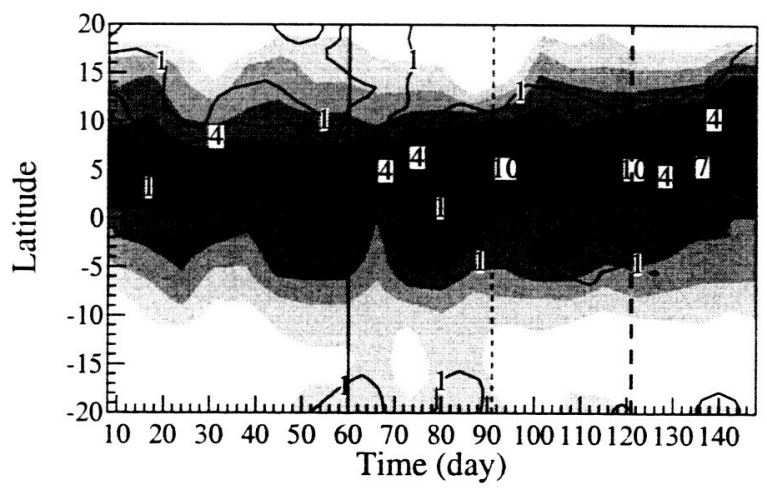

Figure 13: Latitude-time diagram of weekly TRMM rainfall $\left[\mathrm{mm}\right.$ day ${ }^{-1}$; contours; $90.5^{\circ} \mathrm{W}-$ $\left.130.5^{\circ} \mathrm{W}\right]$ and TMI columnar water vapor $\left(\mathrm{mm}\right.$; shades; $90.125^{\circ} \mathrm{W}-130.125^{\circ} \mathrm{W}$ ). 
February
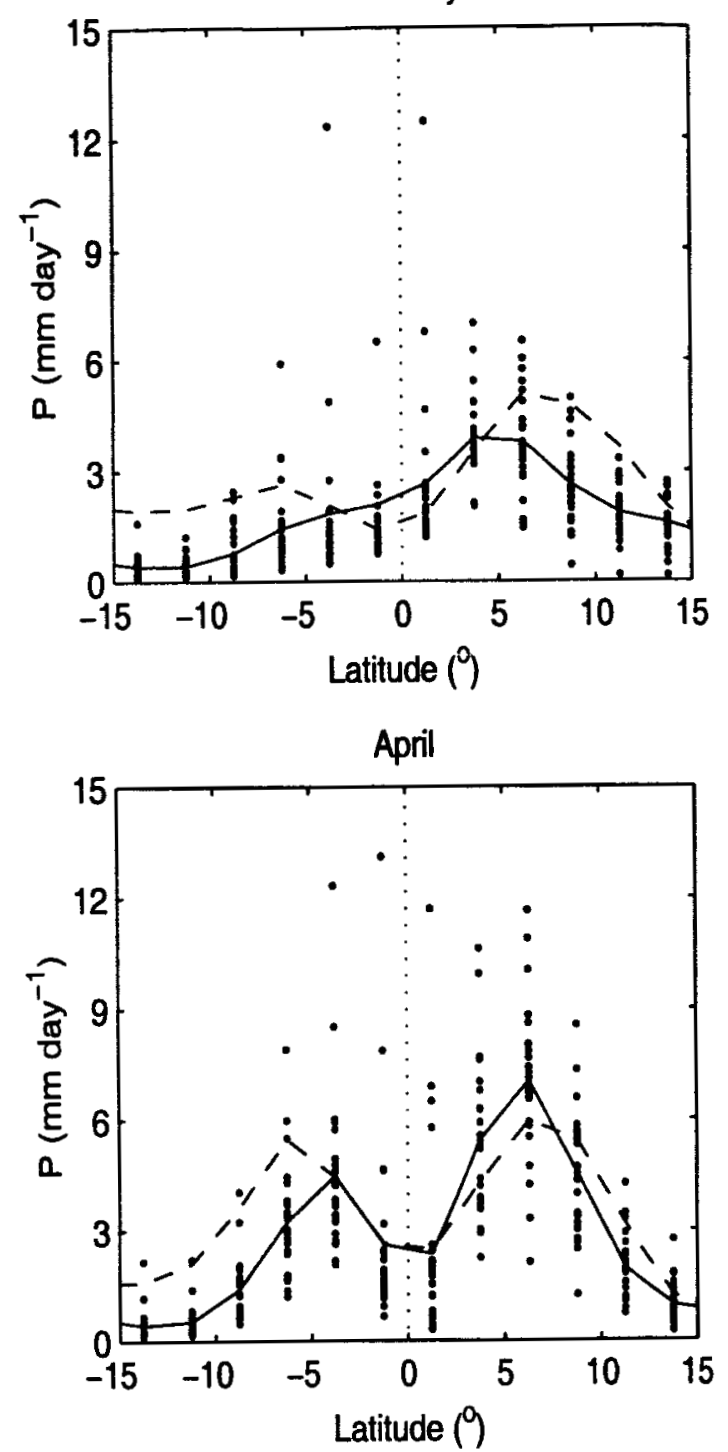
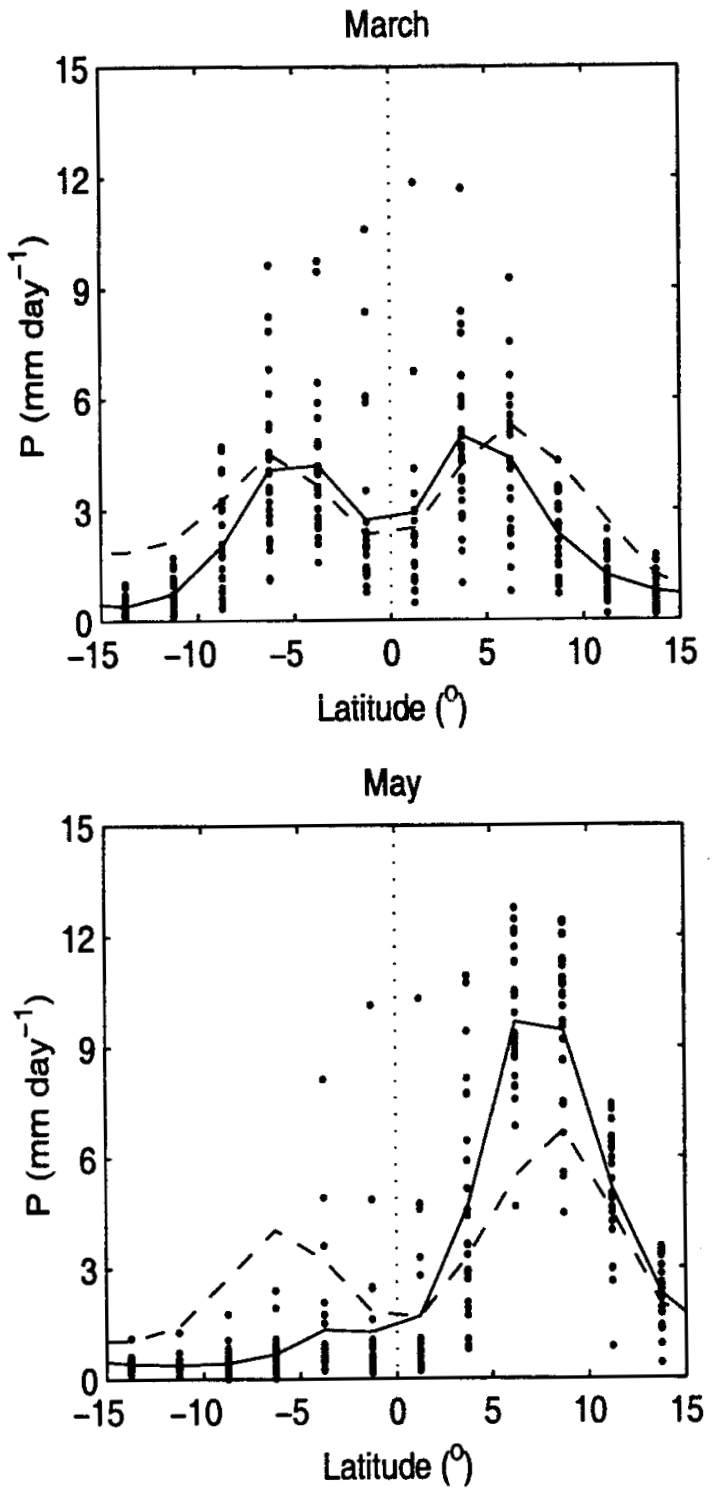

Figure 14: Meridional profiles of monthly rainfall from GPCP (solid lines) and NCEP/NCAR reanalysis project (dashed lines) $\left[P\left(m m d a y^{-1}\right) ; 91.125^{\circ} \mathrm{W}-131.125^{\circ} \mathrm{W}\right]$ during $1979-2003$. Dots denote monthly GPCP rainfall in each year. 
(a) Precipitation

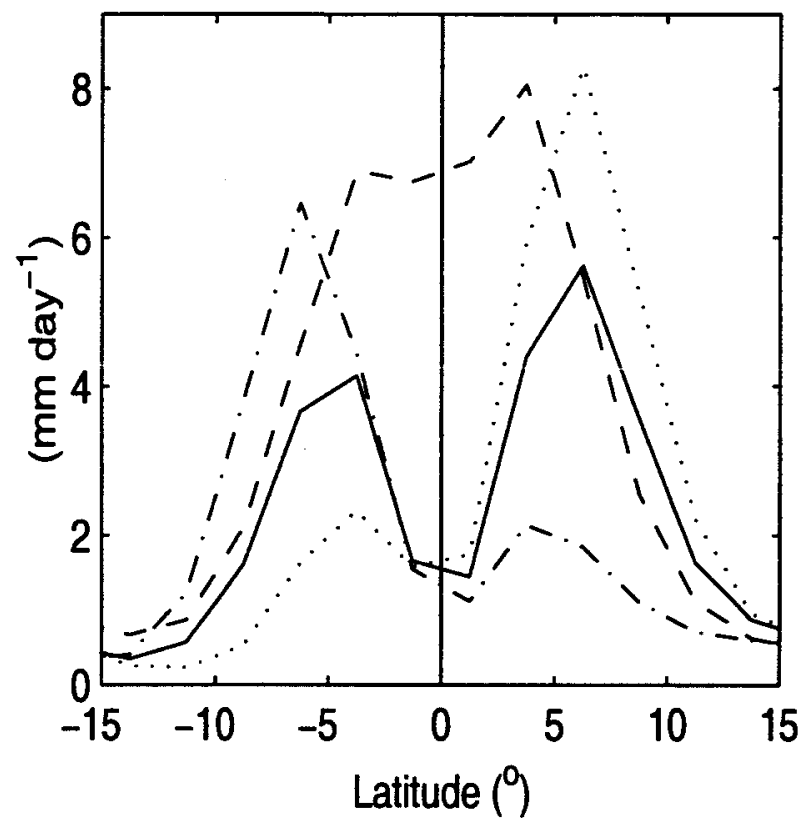

(b) SST

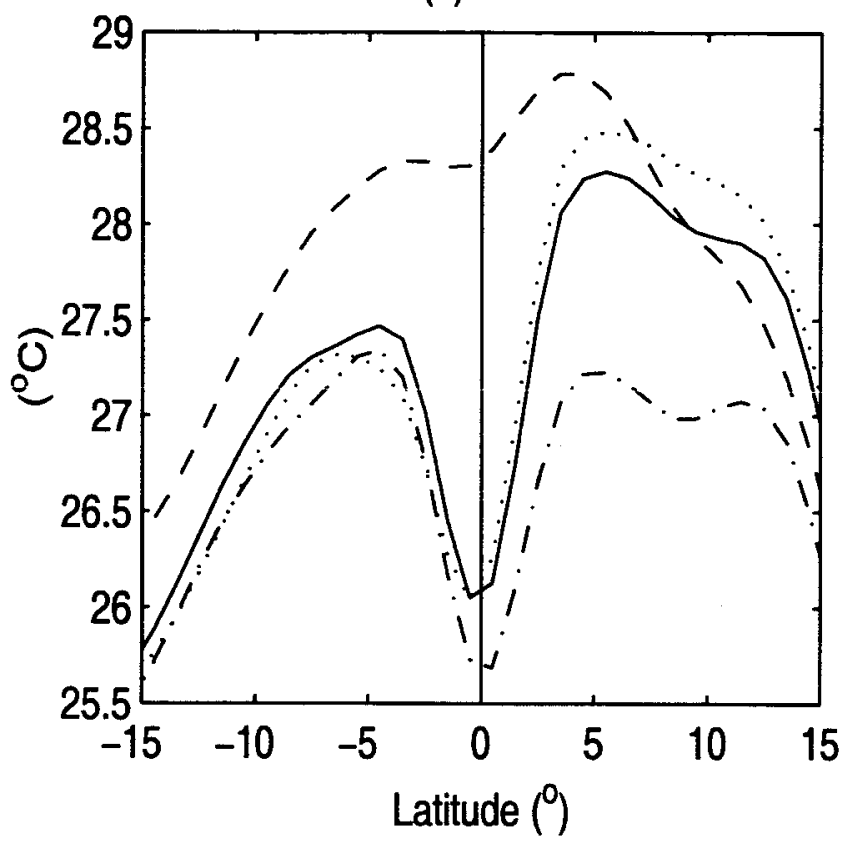

Figure 15: Composite meridional profiles of monthly (a) GPCP rainfall $\left(m m d a y^{-1}\right)$ and (b) Reynolds SST $\left({ }^{\circ} \mathrm{C}\right.$ ) between $91.125^{\circ} \mathrm{W}-131.125^{\circ} \mathrm{W}$ for the four ITCZ types during MarchApril. Solid lines are for Type I, dashed ones for Type II, dashdot ones for Type III, and dotted ones for Type IV. 
(a) Type I

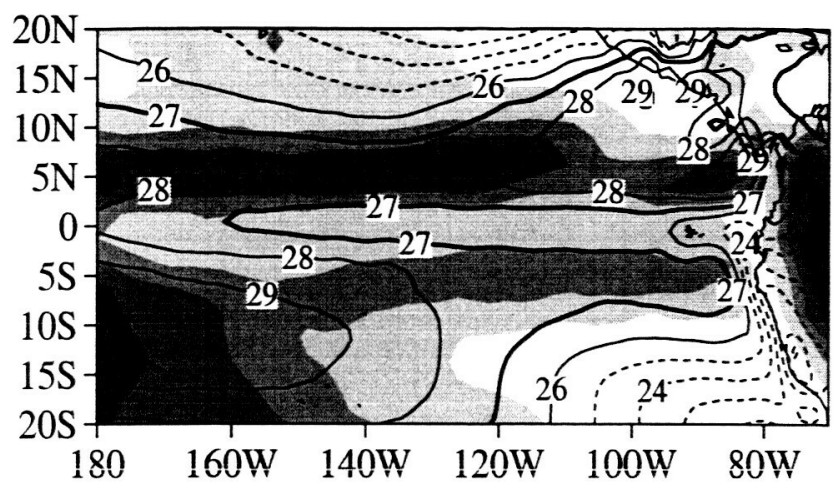

(c) Type III

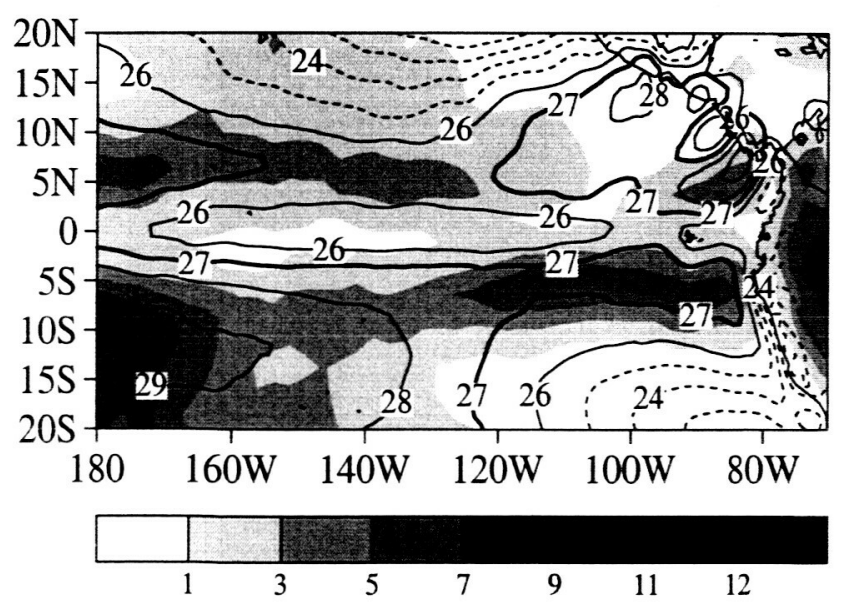

(b) Type II

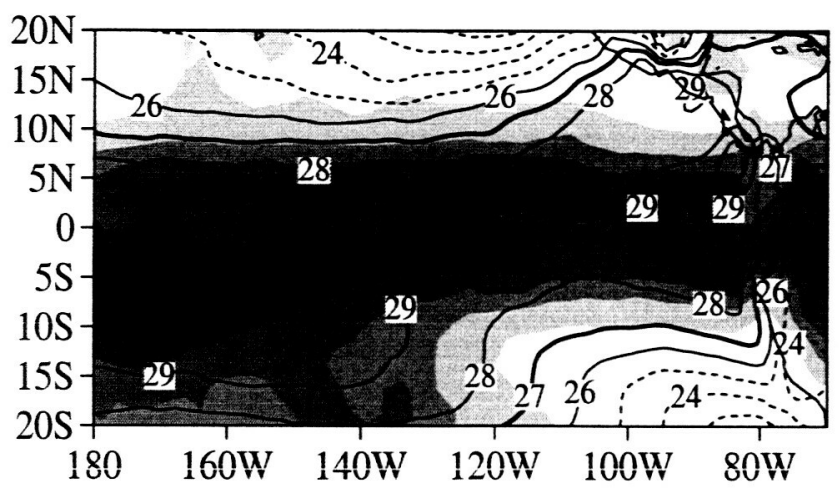

(d) Type IV

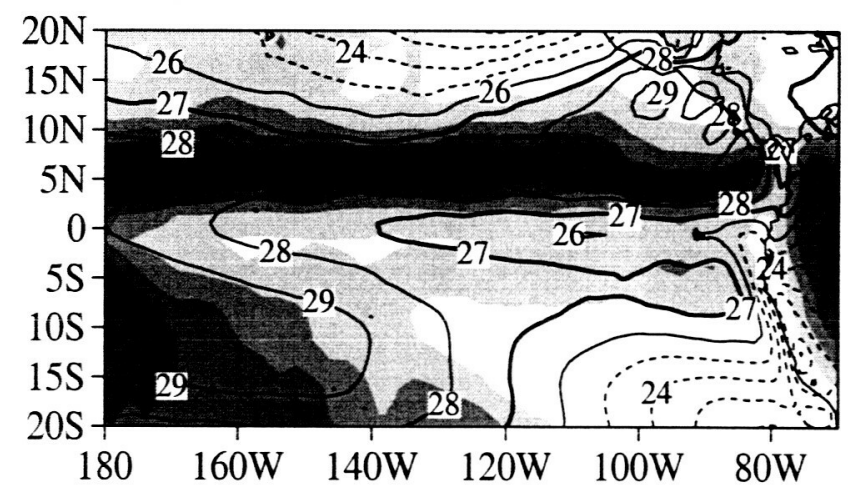

Figure 16: Composite horizontal distributions of monthly GPCP rainfall ( $m m d a y^{-1}$; shades) and Reynolds SST ( ${ }^{\circ} \mathrm{C}$; contours) for the four ITCZ types during March-April. 